\title{
C9orf72 Dipeptide Repeats Cause Selective Neurodegeneration and Cell-Autonomous Excitotoxicity in Drosophila Glutamatergic Neurons
}

\author{
DWangchao $\mathrm{Xu}$ and Jin $\mathrm{Xu}$ \\ Institute of Neuroscience, State Key Laboratory of Neuroscience, Shanghai Institutes for Biological Sciences, Chinese Academy of Sciences, \\ Shanghai 200031, China
}

\begin{abstract}
The arginine-rich dipeptide repeats (DPRs) are highly toxic products from the C9orf72 repeat expansion mutations, which are the most common causes of familial amyotrophic lateral sclerosis (ALS) and frontotemporal dementia (FTD). However, the effects of DPRs in the synaptic regulation and excitotoxicity remain elusive, and how they contribute to the development of FTD is primarily unknown. By expressing DPRs with different toxicity strength in various neuronal populations in a Drosophila model, we unexpectedly found that Glycine-Arginine/Proline-Arginine (GR/PR) with 36 repeats could lead to neurodegenerative phenotypes only when they were expressed in glutamatergic neurons, including motor neurons. We detected increased extracellular glutamate and intracellular calcium levels in GR/PR-expressing larval ventral nerve cord and/or adult brain, accompanied by significant increase of synaptic boutons and active zones in larval neuromuscular junctions. Inhibiting the vesicular glutamate transporter expression or blocking the NMDA receptor in presynaptic glutamatergic motor neurons could effectively rescue the motor deficits and shortened life span caused by poly GR/PR, thus indicating a cell-autonomous excitotoxicity mechanism. Therefore, our results have revealed a novel mode of synaptic regulation by arginine-rich C9 DPRs expressed at more physiologically relevant toxicity levels and provided a mechanism that could contribute to the development of C9-related ALS and FTD.
\end{abstract}

Key words: ALS; C9orf72 dipeptide repeats; cell-autonomous; excitotoxicity; FTD; selective neurotoxicity

Significance Statement

C9orf72 dipeptide repeats (DPRs) are key toxic species causing ALS/FTD, but their roles in synaptic regulation and excitotoxicity are unclear. Using C9orf72 DPRs with various toxicity strength, we have found that the arginine-rich DPRs cause selective degeneration in Drosophila glutamatergic neurons and revealed an NMDA receptor-dependent cell-autonomous excitotoxicity mechanism. Therefore, this study has advanced our understanding of C9orf72 DPR functions in synaptic regulation and excitotoxicity and provided a new mechanism that could contribute to the development of C9-related ALS and FTD.

\section{Introduction}

Hexanucleotide repeat expansion in the C9orf72 (C9) gene is the most common mutation causing familial amyotrophic lateral

Received April 10, 2018; revised June 28, 2018; accepted July 5, 2018.

Author contributions: W.X. and J.X. designed research;W.X. performed research; W.X. and J.X. analyzed data; J.X. wrote the paper.

This work was supported by National Science Foundation of China Grant 81771425 to J.X. [principal investigator (PI)] and Chinese Ministry of Science and Technology Grant $2015 Z$ X09102005002 to J.X. (co-PI). We thank Bloomington Drosophila Stock Center; Core Facility of Drosophila Resource and Technology at Shanghai Institute of Biochemistry and Cell Biology; and Drs. Adrian Issacs, Aike Guo, and Fude Huang for various fly lines. We also thank Dr. Aaron DiAntonio for generously providing anti-vGlut antibody.

The authors declare no competing financial interests.

Correspondence should be addressed to Dr. Jin Xu, Institute of Neuroscience, Shanghai Institutes for Biological Sciences, 320 Yue Yang Road, Shanghai 200031, China. E-mail: jin.xu@ion.ac.cn.

DOI:10.1523/JNEUROSCI.0908-18.2018

Copyright $\odot 2018$ the authors $\quad 0270-6474 / 18 / 387741-12 \$ 15.00 / 0$ sclerosis (ALS) and frontotemporal dementia (FTD; DeJesusHernandez et al., 2011; Renton et al., 2011). Numerous studies have been conducted to understand the biological consequences of the C9 repeat expansion, and three major pathogenic outcomes have become consensus, namely the generation of toxic dipeptide repeats (DPRs), the formation of RNA foci, and the loss of C9 gene functions (Gendron and Petrucelli, 2018). Recent studies have also demonstrated that arginine-rich DPRs (poly Glycine-Arginine/ Proline-Arginine (GR/PR)) are one of the major sources of neurotoxicity (Kwon et al., 2014; Mizielinska et al., 2014; Tran et al., 2015). GR/PR could target nucleopore complexes and affect the nuclearcytoplasmic trafficking of RNA and proteins (Freibaum et al., 2015; Jovicic et al., 2015; Zhang et al., 2015; Boeynaems et al., 2016; Shi et al., 2017). In addition, poly GR/PR interact with stress granule components and affect the formation and dynamics of stress granules (Tao et al., 2015; Lee et al., 2016; Lin et al., 2016; Boeynaems et al., 
2017; Markmiller et al., 2018). Therefore, the gradual accumulation of those highly toxic DPRs, even at very low levels, could render neurons vulnerable.

Synaptic dysfunction usually occurs before pathological changes in many neurodegenerative diseases (Cleveland and Rothstein, 2001; Selkoe, 2002; Raymond et al., 2011; Picconi et al., 2012), and altered excitotoxicity is a key mechanism contributing to motor neuron degeneration in ALS (Rothstein et al., 1990; Taylor et al., 2016). In fact, riluzole, one of the two Food and Drug Administration-approved drugs for ALS, blocks glutamate transmission (Bensimon et al., 1994). Whether C9 repeat expansion products can affect the synaptic function or excitotoxicity is not entirely clear (Starr and Sattler, 2018). Mouse models with bacterial artificial chromosome containing human C9 repeat expansion did not show consistent change of synaptic structure or denervation of the cholinergic neuromuscular junctions (NMJs; O’Rourke et al., 2015; Peters et al., 2015; Liu et al., 2016). In Drosophila models, overexpression of C9 repeat expansion with RNA and/or protein products in glutamatergic motor neurons caused NMJ structure damage (Freibaum et al., 2015; Perry et al., 2017). As most of these models produce highly toxic C9 constructs leading to pupal lethality, the effects of $\mathrm{C} 9$ repeat expansion products at more physiological expression levels are unknown. The roles of C9 repeat expansion in excitotoxicity are gradually being recognized. A few studies suggested increased expression of glutamate receptors in C9 patient-derived induced pluripotent stem cells (iPSCs) motor neurons (Donnelly et al., 2013; Selvaraj et al., 2018; Shi et al., 2018). Furthermore, the splicing of EAAT2 could be affected by C9 DPR (Kwon et al., 2014) and lead to decreased glutamate uptake by astrocytes and increased excitotoxicity in motor neurons (Shi et al., 2018). However, most of the studies on C9 repeat expansion products have been focused on the survival and function of motor neurons, and the contribution of those toxic products to neurons affected in FTD, such as excitatory spindle neurons, is unknown.

Drosophila is a valuable and popular model to study C9 repeat expansion toxicity ( $\mathrm{Xu}$ et al., 2013; Mizielinska et al., 2014; Freibaum et al., 2015; Zhang et al., 2015; Lee et al., 2016). In many of Drosophila studies, compound eyes were used as an efficient system to study neurotoxicity and to identify genetic suppressors of C9 toxicity. However, this system may not sufficiently reflect the roles of C9 repeat expansion products in the CNS. In this study, we aimed to evaluate the effects of C9 mutations in various neuronal populations in Drosophila CNS. We focused on C9 DPRs as they have emerged as key toxic C9 repeat expansion species and assessed the effects of DPRs at various toxicity strengths. Surprisingly, we found selective neurotoxicity of arginine-rich DPRs in glutamatergic neurons. We also uncovered that cell-autonomous excitotoxicity in glutamatergic neurons was the culprit.

\section{Materials and Methods}

Fly stocks and the generation of new Drosophila transgenic lines. UAS-DPR transgenic flies and DPR constructs were described previously (Mizielinska et al., 2014). To generate the transgenic flies with UAS-GFP-DPRs, DPR constructs were subcloned first into pEGFP-C1 and then into pUASTattB vector for expression in flies. Transgenic fly lines were generated by phiC31-integrase-mediated, site-directed insertion into the 25C6 locus. The embryo injection was performed at the Drosophila core facility at Shanghai Institutes for Biological Sciences. W[1118], GMR-Gal4, ElavC155-Gal4, ChAT-Gal4, and UAS-mCD8:: GFP were kind gifts from Dr. Fude Huang (Shanghai Advanced Research Institute, Shanghai, China). UAS-GCaMP6S was generously provided by Dr. Aike Guo (Institute of Neuroscience, Chinese Academy of Sci-
Table 1. The pupal viability of flies with DPRs expressed in various neuronal types

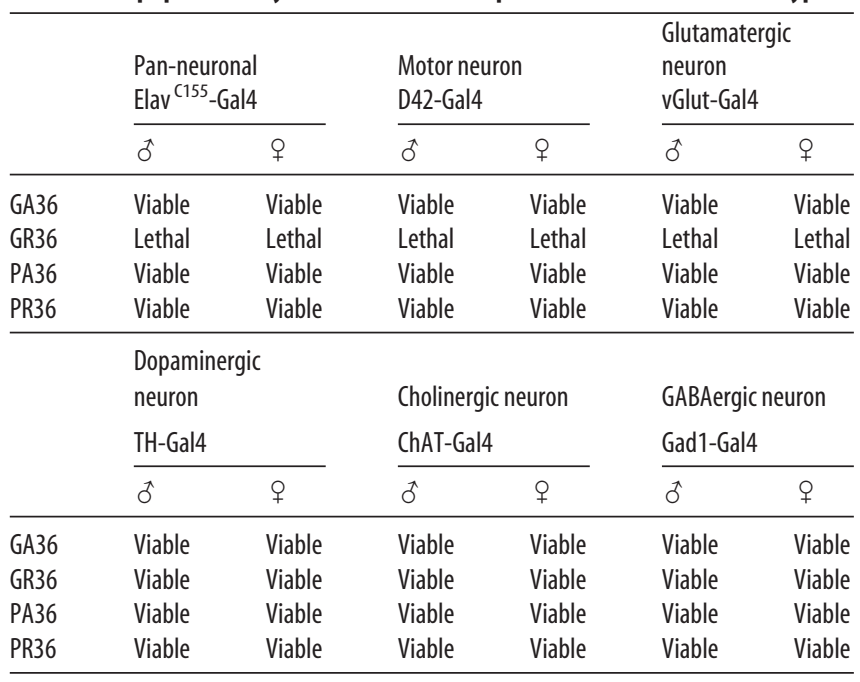

ences). $\left.\mathrm{w}^{*}{ }^{*}\right] \mathrm{P}\{\mathrm{w}[+\mathrm{mW} \cdot \mathrm{hs}]=\mathrm{GawB}\} \mathrm{D} 42$ (BDSC catalog \#8816, RRID: BDSC_8816), $\left.\mathrm{w}^{*}\right] ; \mathrm{P}\{\mathrm{w}[+\mathrm{mC}]=$ ple-GAL4.F 3 (BDSC catalog \#8848, RRID: BDSC_8848), $\mathrm{w}[1118] ; \mathrm{P}\{\mathrm{w}[+\mathrm{mW} . \mathrm{hs}]=\mathrm{GawB}\} \mathrm{vGlut}[\mathrm{OK} 371]$ (BDSC catalog \#26160, RRID:BDSC_26160), $\mathrm{P}\{\mathrm{w}[+\mathrm{mC}]=$ Gad1-GAL4.3.098 $\} 2 /$ CyO (BDSC catalog\#51630, RRID:BDSC_51630), y1 w; P\{CCAP-GAL4.P $\} 16 / C y O$ (BDSC catalog \#25685, RRID:BDSC_25685), $\left.\mathrm{w}^{[*}\right] ; \mathrm{P}\{\mathrm{y}[+\mathrm{t} 7.7] \quad \mathrm{w}[+\mathrm{mC}]=$ vGlut-GAL80.V\}attP40/CyO; TM6B, Tb[1]/TM3, Sb[1] (BDSC catalog \#58448, RRID:BDSC_58448), $w[1118]$; PBac\{y[+mDint2] $\mathrm{w}[+\mathrm{mC}]=$ 20XUAS-iGluSnFR.A184L\}VK00005 (BDSC catalog \#59613, RRID; BDSC_59613), y1 sc ${ }^{\star}$ v1; P\{TRiP.HMS02011\}attP2 (BDSC catalog \#40845, RRID:BDSC_40845), y1 sc ${ }^{\star}$ v1; P\{TRiP.HMS02175\}attP40 (BDSC catalog \#40927, RRID:BDSC_40927), y[1] v[1]; $\mathrm{P}\{\mathrm{y}[+\mathrm{t} 7.7] \mathrm{v}[+\mathrm{t} 1.8]=$ TRiP.JF01961 $\}$ attP2 (BDSC catalog \#25941, RRID:BDSC_25941), and w1118; P\{UAS-polyGR.PO-100\}attP40 (BDSC catalog \#58696, RRID:BDSC_58696) were obtained from Bloomington Drosophila Stock Center (BDSC). All

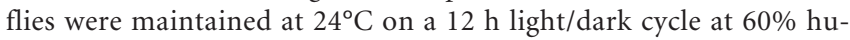
midity on a standard medium.

Climbing assay. Briefly, 10 male flies aged $7 \mathrm{~d}$ were transferred to the testing vials. Flies were tapped down to the bottom of the vials, and the videos of the climbing behavior were recorded. The height of each fly at $5 \mathrm{~s}$ was determined. A total of three trials were performed for each vial, and the mean height for flies in each vial was calculated. At least three vials were used for each genotype.

Life span assay. Flies were collected $5 \mathrm{~d}$ after eclosion and transferred to tubes at a density of 20 flies per vial. Every $5 \mathrm{~d}$, the flies were moved to fresh vials, and the number of dead flies was scored. At least three vials were used for each genotype.

Immunoblotting, immunohistochemistry, and imaging. Twenty-five male fly heads per genotype were collected after incubation in nitrogen liquid and homogenized in RIPA lysis buffer. The procedures for Western blot were described previously (Wang et al., 2016). Antibodies used included anti-vesicular glutamate transporter (vGlut; kindly provided by Dr. Aaron DiAntonio; Daniels et al., 2008), $\beta$-tubulin antibody (1:3000, Abmart), and HRP-conjugated secondary antibodies (Jackson ImmunoResearch Laboratories).

Wandering third instar larvae and adult brain were dissected in PBS and fixed with either $4 \%$ paraformaldehyde or Bouin's fixative solution (for NMJ staining) for $25 \mathrm{~min}$. After fixation, the samples were washed with $0.3 \%$ Triton X-100 in PBS (PBST), followed by blocking and antibody incubation using PBST with 5\% BSA as diluent. The primary antibodies used included the following: chicken anti-GFP (1:500, catalog \#A10262, Thermo Fisher Scientific; RRID:AB_2534023), rabbit antityrosine hydroxylase (1:400, catalog \#AB152, Millipore; RRID: AB_390204), mouse anti-discs large 1 (DLG 1; 1:100, catalog \#4F3 antidiscs large, Developmental Studies Hybridoma Bank (DSHB); RRID: AB_528203), rabbit anti-vGlut (1:1000), and mouse anti-bruchpilot (Brp; 1:200, catalog \#nc82, DSHB; RRID:AB_2314866). After primary 


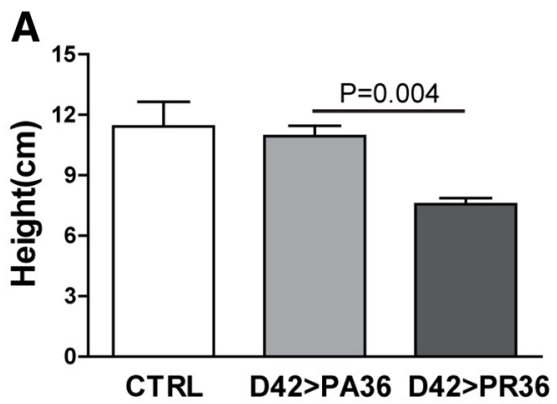

C
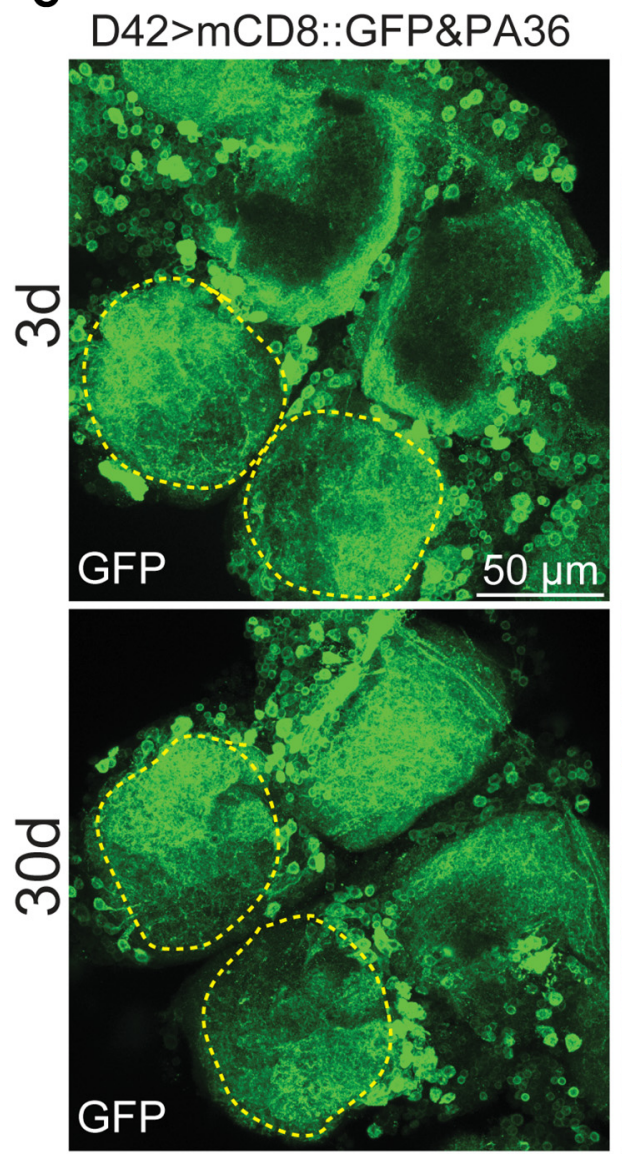

B
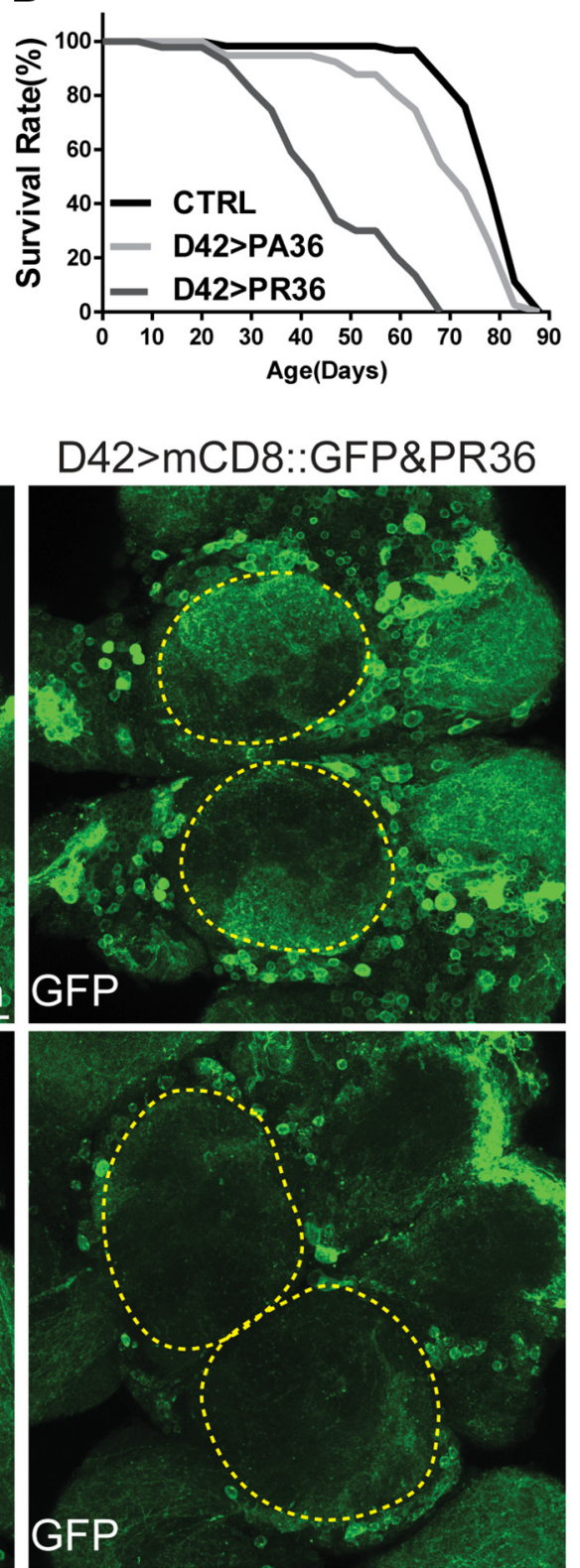

D

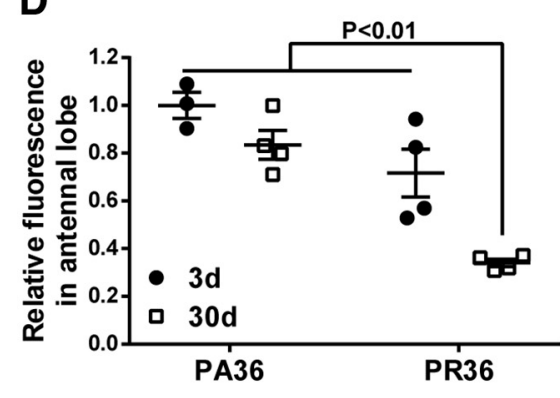

E
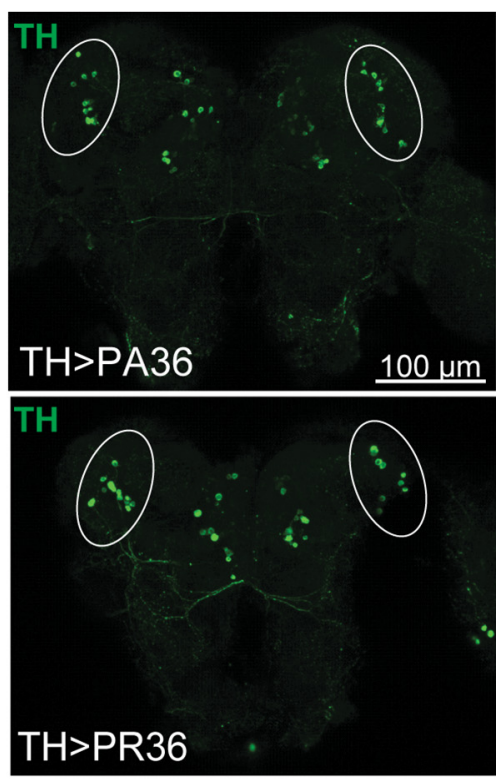

$\mathbf{F}$

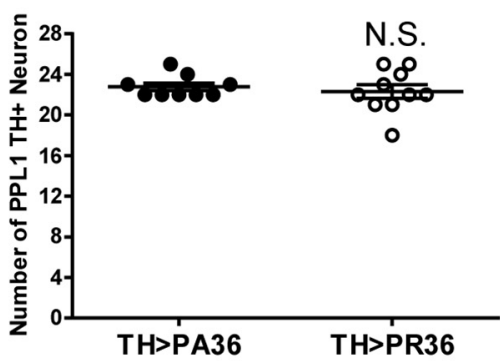

Figure 1. PR36 causes selective neuronal death in motor neurons but not in dopaminergic neurons. $A, B$, The effects of motor neuron-expressed PA36 or PR36 on climbing and life span. Male, control (CTRL) genotype: D42-Gal4/+. Mean \pm SEM, $n=3$ tubes, one-way ANOVA. C, Representative images showing the loss of motor neurons expressing PR36 at indicated ages. As reliable antibodies for DPRs or for Drosophila motor neurons were not available, D42 >mCD8::GFP was used to label the motor neuron population. Note that PR36 caused motor neuron loss when compared with the control PA36, and the neuronal loss progressed with aging. Decreased fluorescent intensity at antennal lobe (indicated by the dashed lines), a neuropil of motor neurons, was observed in PR36-expressing flies. The images were taken under identical parameters including the equivalent value of laser intensity, gain, offset, and pinhole and were shown as Z-stack projection. $\mathbf{D}$, The quantification of the fluorescence in antennal lobe. Mean \pm SEM, $n=4$ male flies, two-way ANOVA.E, F, PR36 failed to cause neuronal loss in dopaminergic neurons in 30-d-old flies. Dopaminergic neurons in posterior brain were labeled with an anti-tyrosine hydroxylase (TH) antibody. Circles indicate protocerebral posterior lateral 1 (PPL1) clusters of TH-positive neurons. The quantification of the PPL1 TH-positive neurons is shown in $\boldsymbol{F}$. Mean \pm SEM, $n \geq 9$ male flies for each genotype, unpaired $t$ test.

antibody incubation at $4^{\circ} \mathrm{C}$ overnight, Cy3-conjugated anti-HRP (1:500, catalog \#123-165-021, Jackson ImmunoResearch Laboratories; RRID: AB_2338959) or fluorescent-labeled secondary antibodies (1:500, Invitrogen) were used for $2 \mathrm{~h}$ at room temperature. Images were acquired with a confocal microscope and processed with Fiji software (Fiji; RRID:SCR_002285).

Glutamate and calcium live imaging. For in vivo imaging, first instar larvae were immobilized by embedding them in halocarbon oil under a cover glass. For ex vivo imaging, larval ventral nerve cord and male adult brain were dissected in extracellular solution $[6.0193 \mathrm{~g} / \mathrm{L} \mathrm{NaCl}, 0.2237$ g/L KCl, 1.146 g/L N-tris(hydroxymethyl)methyl-2-aminoethanesulfonic acid (TES), $2.7384 \mathrm{~g} / \mathrm{L}$ trehalose, $1.8016 \mathrm{~g} / \mathrm{L}$ glucose, $2.1843 \mathrm{~g} / \mathrm{L}$
$\mathrm{NaHCO}_{3}, 0.12 \mathrm{~g} / \mathrm{L} \mathrm{NaH} \mathrm{PO}_{4}, 0.2205 \mathrm{~g} / \mathrm{L} \mathrm{CaCl}_{2}, 0.3808 \mathrm{~g} / \mathrm{L} \mathrm{MgCl}_{2}$ in double-distilled $\mathrm{H}_{2} \mathrm{O}\left(\mathrm{ddH}_{2} \mathrm{O}\right), \mathrm{pH}$ 7.3] and embedded in Agarose L.M.P. After gelation, the samples were immersed in extracellular solution, followed by imaging with a water objective (Olympus). After scanning the whole sample at $z$-axis, the middle plane was identified for long-term live imaging (30 s).

Quantitative PCR analysis. Twenty fly heads were collected and homogenized in Trizol reagent (Invitrogen) for RNA extraction. For quantitative PCR, $1 \mu \mathrm{g}$ of RNA was reverse transcribed (Takara), followed by PCR amplification with SYBR green (CFX-connector, Bio-Rad). Gene expression data were calculated by the delta-delta Ct method. GAPDH was used as reference control. The sequences of all the primers are available upon request. 
A
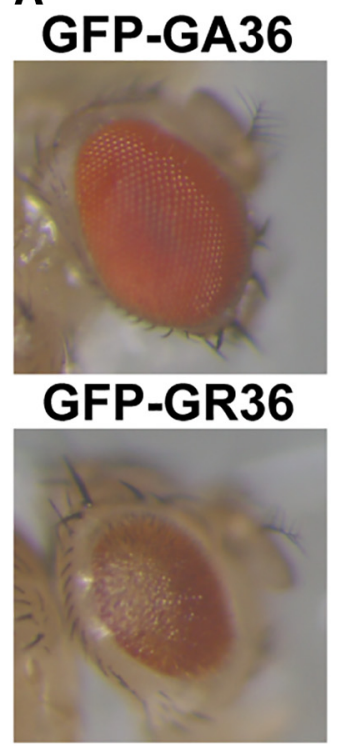

GFP-PR36
B

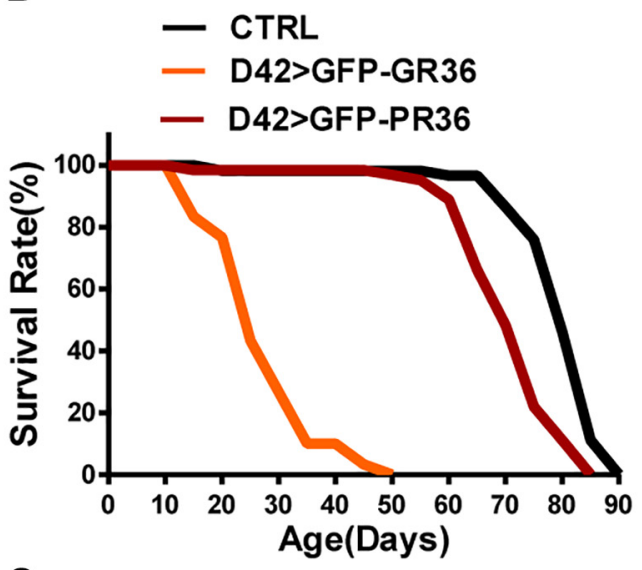

C

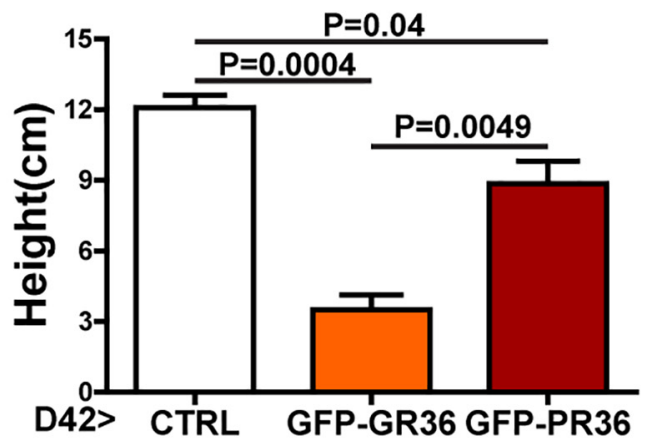

D

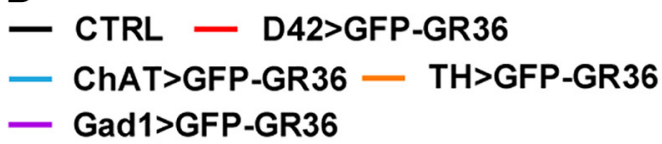

- Gad1>GFP-GR36

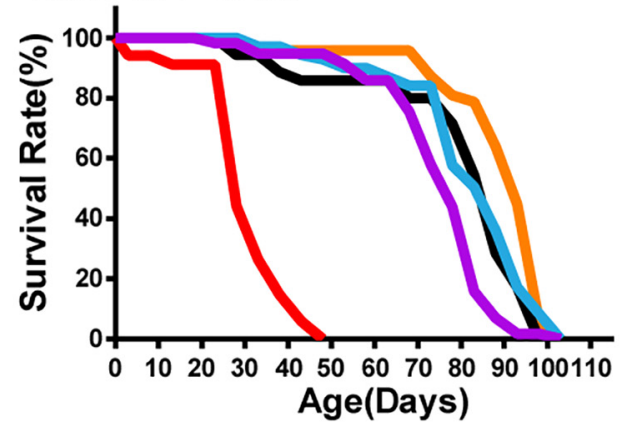

E
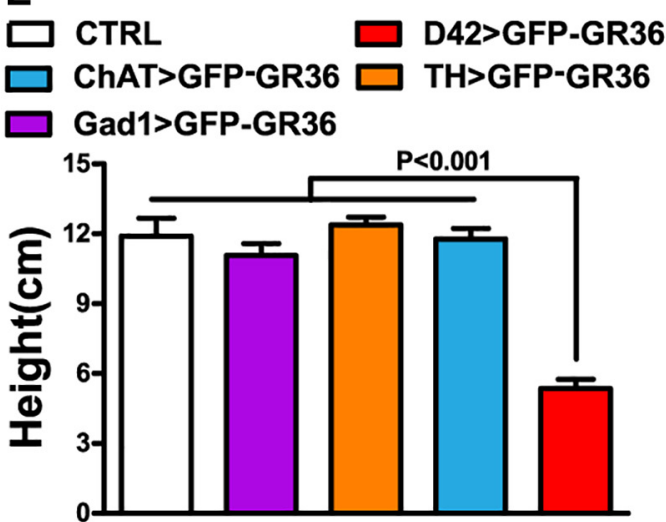

Figure 2. Expression of GFP-GR36 in glutamatergic motor neurons causes neurodegenerative phenotypes. $A$, Eye phenotypes caused by GFP-DPR expression under the control of GMR-Gal4. $B, C$, Life span and climbing ability of the wild-type flies and flies with motor neuron-specific expression of GFP-GR36 or GFP-PR36. Male, control genotype: D42-Gal4/ + . Mean \pm SEM, $n=3$ tubes for each genotype, one-way ANOVA. D, E, Life span and climbing assays for flies with indicated genotype. Male, control genotype: UAS-GFP-GR36/ + . Mean \pm SEM, $n=3$ tubes for each genotype, one-way ANOVA. CTRL, Control.

A CTRL Elav ${ }^{\mathrm{C} 155}>$ GFP-GR36 Elav $^{\mathrm{C} 155}>$ GFP-GR36; vGlut ${ }^{\mathrm{Gal}} 30$

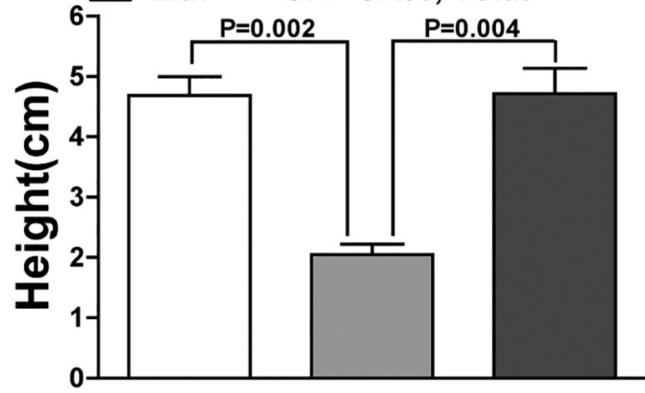

B

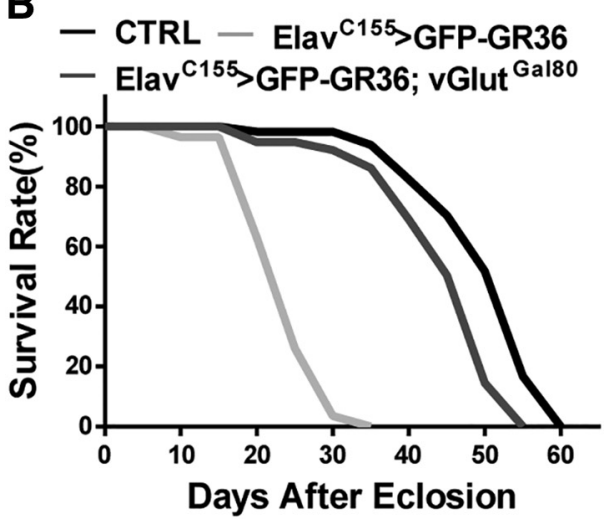

Figure 3. Suppressing the expression of GFP-GR36 in glutamatergic neurons blocks the toxicity. Expression of Gal80 in glutamatergic neurons rescued the GFP-GR36-caused climbing deficits ( $\boldsymbol{A}$ ) and shortened life span (B). Female, control genotype: Elav ${ }^{\mathrm{C} 155}$-Gal4/+. Mean $\pm \mathrm{SEM}, n=3$ tubes for each genotype, one-way ANOVA.

Drug treatment. Memantine hydrochloride (Sigma) was dissolved in $\mathrm{dd}_{2} \mathrm{O}$ and added to a final concentration of $10 \mu \mathrm{M}$ drug in standard fly food. The feeding was started from larval stage.

Experimental design and statistical analysis. The $n$ number and gender of flies used in this study were described in the corresponding figure legends or methods. Most of the data were obtained by objective measures, such as mRNA gene expression by qPCR, fly life span. Fly motor function was assessed using objective video recording. Confocal images were analyzed by Fiji software (Fiji; RRID:SCR_002285). Quantification for Western blot was performed by Quantity One 1-D Analysis Software (Bio-Rad; RRID:SCR_014280). The statistical methods were demonstrated in corresponding figure legends. Data analysis was performed by using GraphPad Prism (GraphPad Software; RRID:SCR_002798). $p<$ 0.05 was considered as a significant change.

\section{Results}

To characterize the neurotoxicity of C9orf72 DPRs in the CNS in detail, we use the Gal4-UAS system (Brand and Perrimon, 1993) 
A

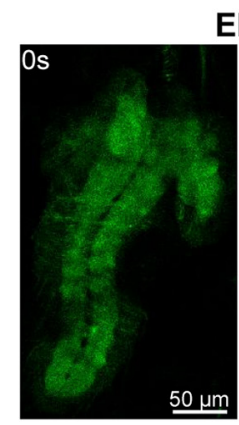

Elav $^{\mathrm{C} 155}>$ iGlusnFR 1st instar larva
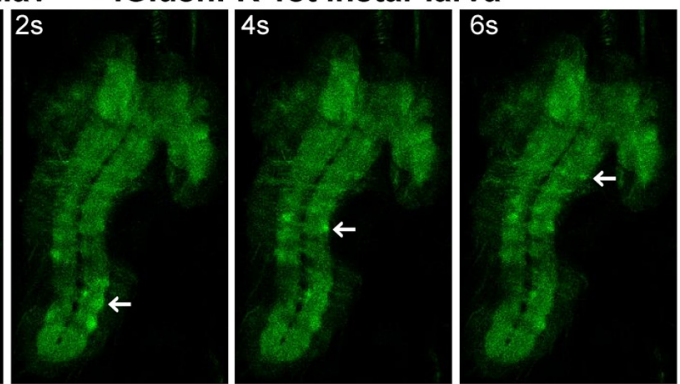

C

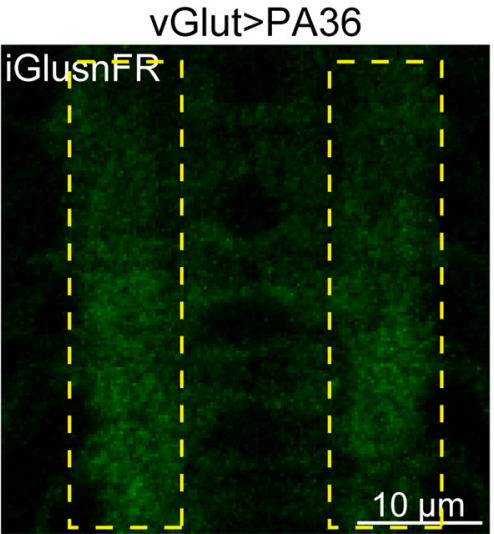

E

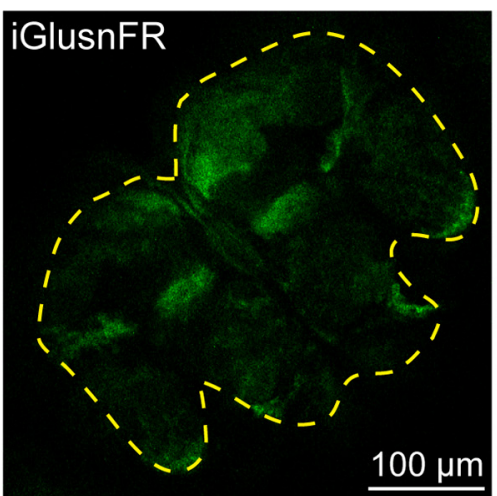

$\mathbf{G}$

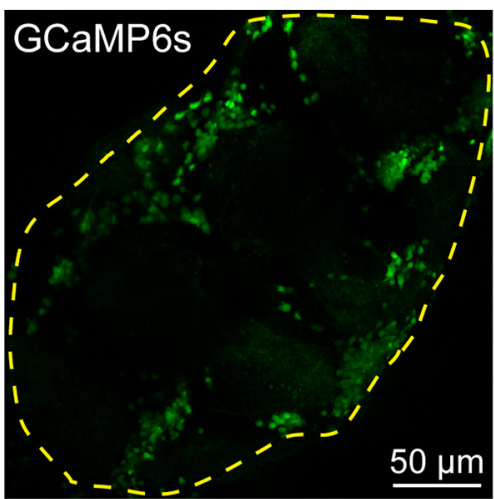

vGlut>PR36
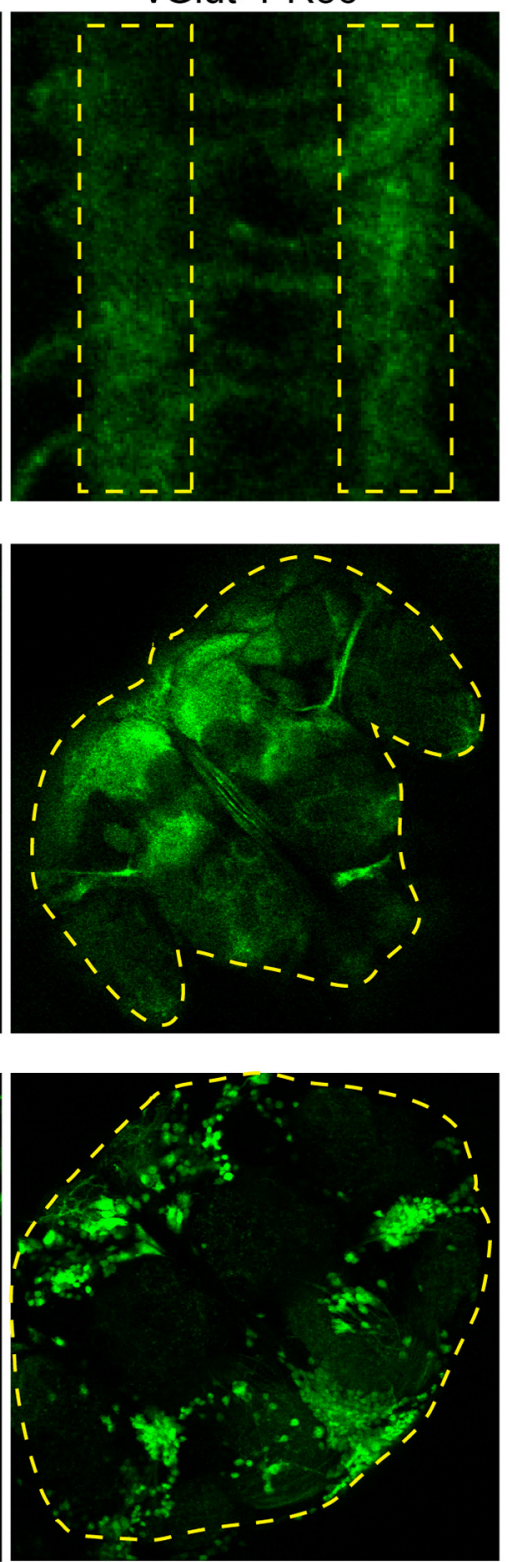

B

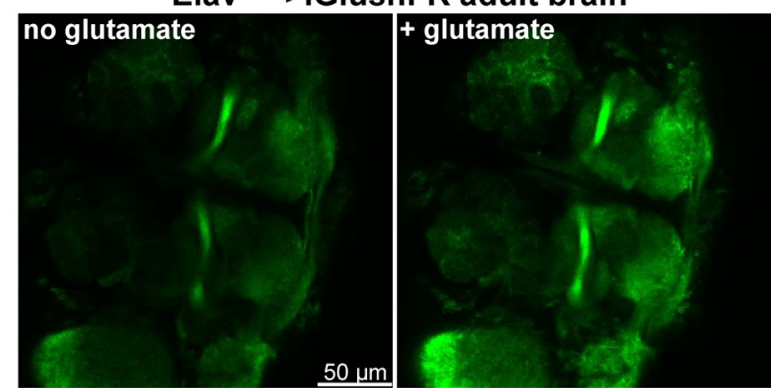

D
Ventral nerve cord

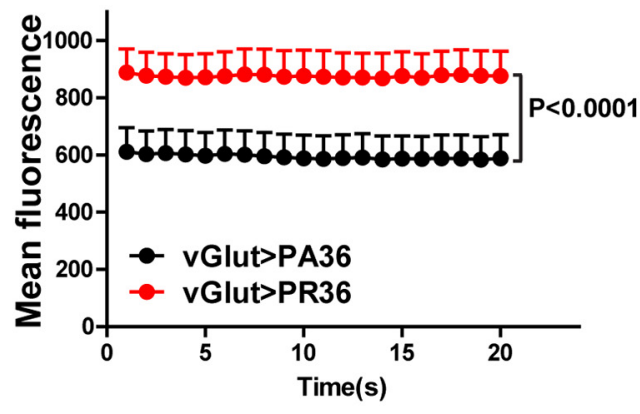

$\mathbf{F}$

\section{Brain}

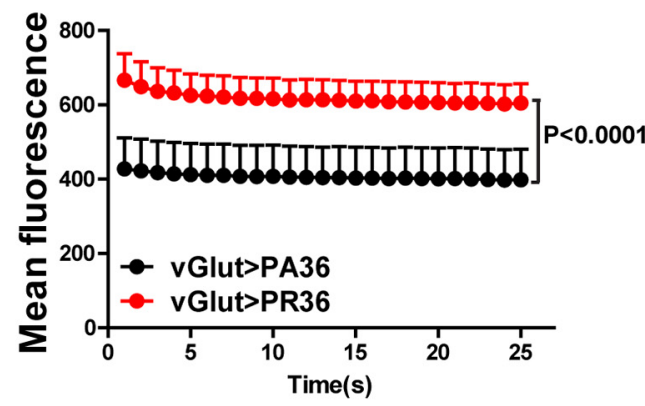

H

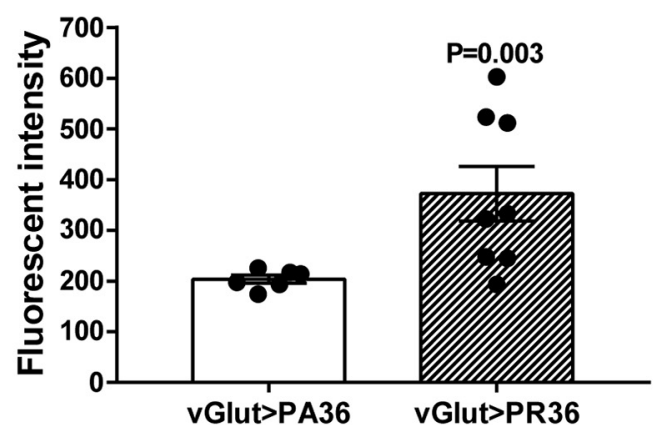

Figure 4. PR36 expression increases levels of extracellular glutamate and intracellular calcium. $A$, In vivo long-term imaging of first instar larvae with pan-neuronal expression of iGlusnFR showed the glutamate wave along ventral nerve cord (VNC) while larva was crawling. Arrows indicate the signals of the iGlusnFR sensor. $B$, Ex vivo imaging of adult brains before or after $5 \mathrm{~mm}$ glutamate treatment. $\boldsymbol{C}, \boldsymbol{D}$, Representative images showing the signals of iGluSnFR in ventral nerve cord of third instar larvae with the indicated genotype. Dashed rectangles indicate the quantification areas. The quantifications are shown in $\boldsymbol{D}$. Mean $\pm \mathrm{SEM}, n=7$ individual larvae, unpaired $t$ test. $\boldsymbol{E}, \boldsymbol{F}$, Representative images showing the signals of iGluSnFR in adult brain with the indicated genotype. The dashed areas indicate the quantification areas. The quantifications are shown in $\boldsymbol{F}$. Mean \pm SEM, $n=4$ male flies, unpaired $t$ test. $G, \boldsymbol{H}, Z$-projection images of calcium signals in glutamatergic neurons of adult brain with the indicated genotype. The dashed areas indicate the quantification areas. The quantifications are shown in $\boldsymbol{H}$. Mean \pm SEM, $n=6$ male flies for PA36 and $n=8$ male flies for PR36, unpaired $t$ test. 


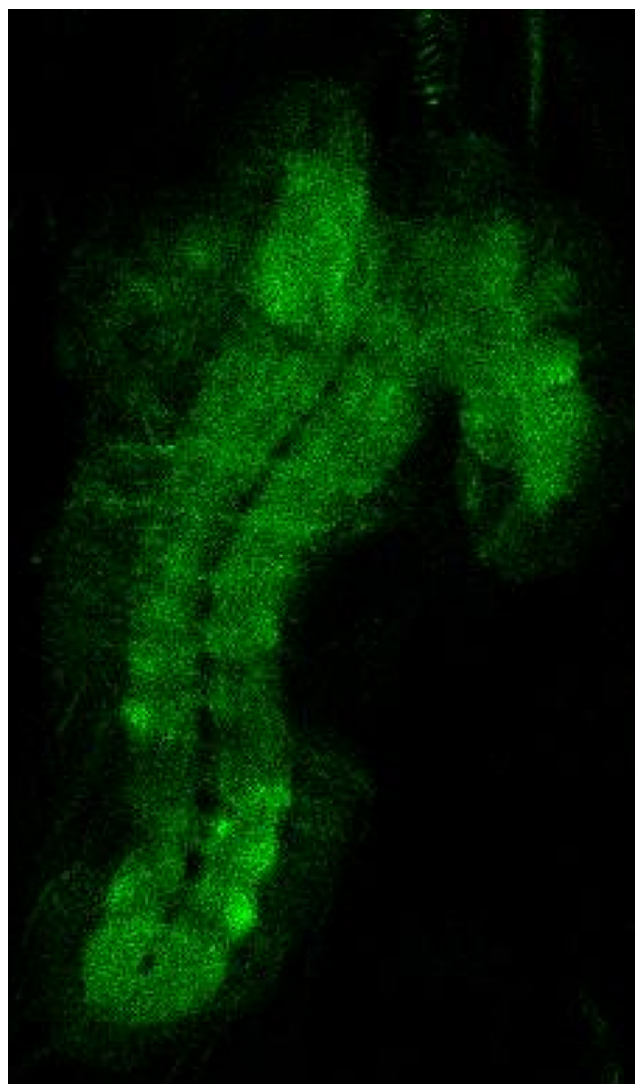

Movie 1. Time-lapse imaging of intact first instar larva. Panneuronal expression of iGlusnFR showed the synchronized propagation of glutamate signal with body wall movements.
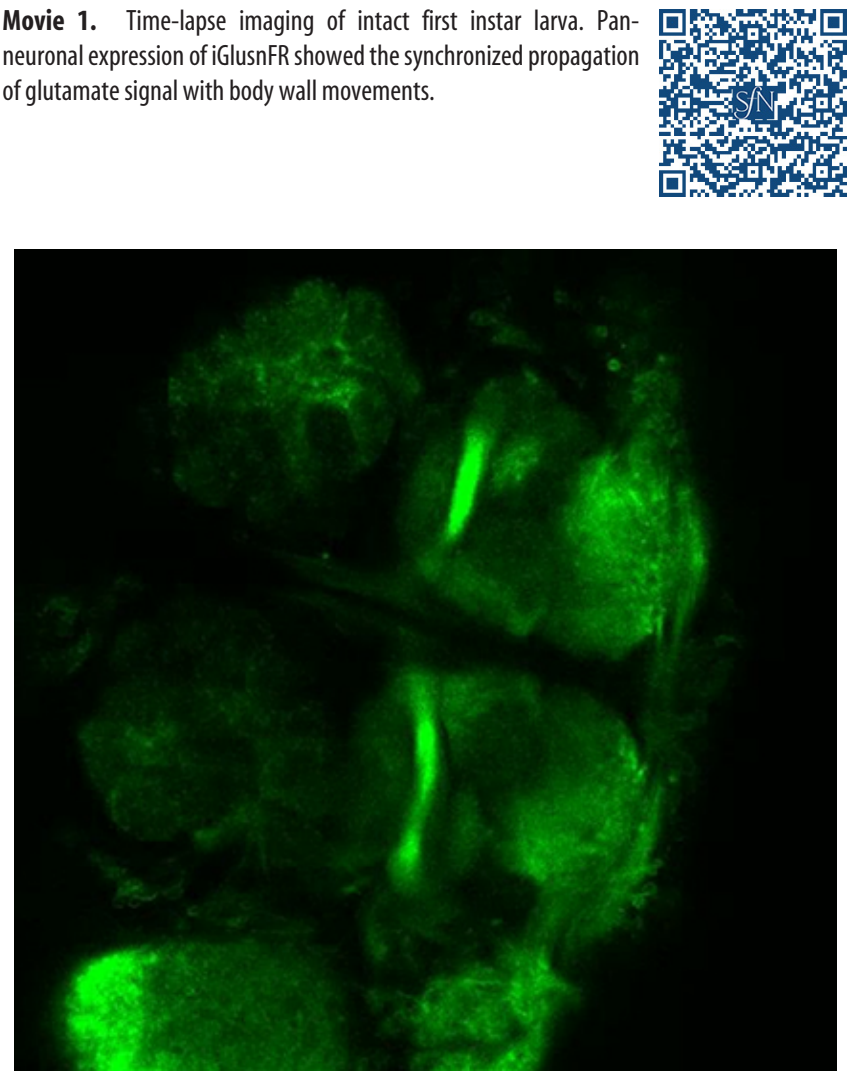

Movie 2. Time-lapse imaging of ex vivo Drosophila brain before or after glutamate treatment. The fluorescence of iGlusnFR showed robust elevation after adding glutamate with the final concentration at $5 \mathrm{~mm}$.

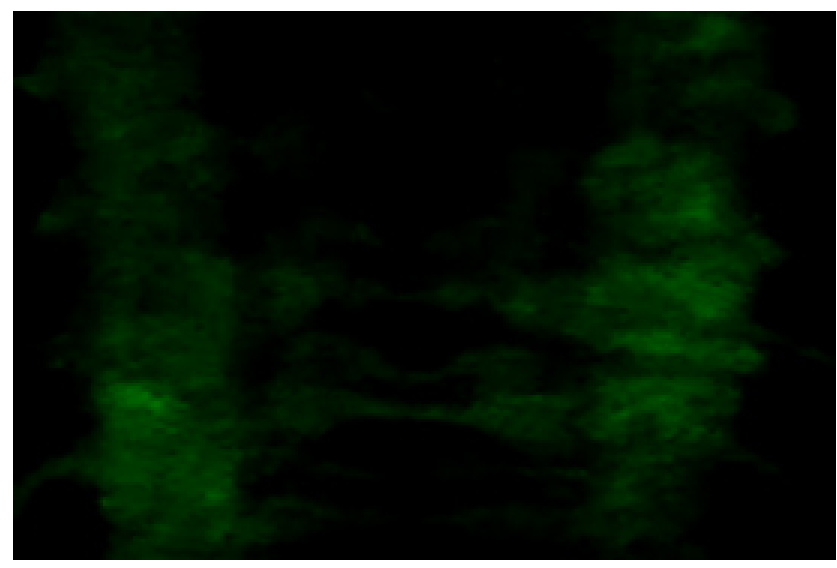

Movie 3. Time-lapse imaging of ex vivo ventral nerve cord of PA36expressing third instar larva. Please note that the fluorescence was transiently increased in local areas, indicating local firings.
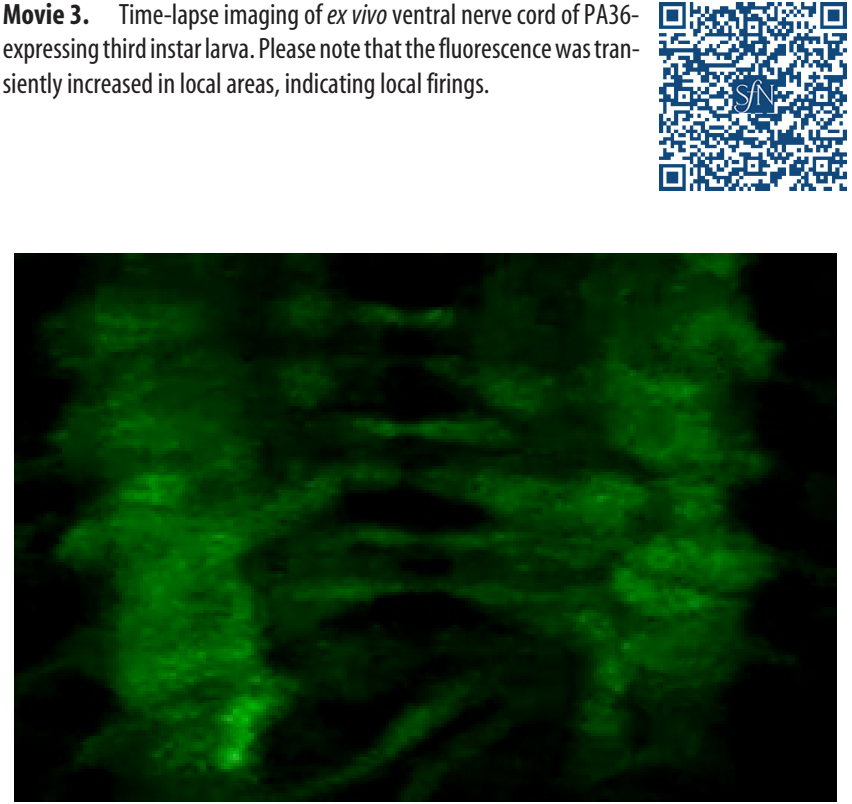

Movie 4. Time-lapse imaging of ex vivo ventral nerve cord of PR36expressing third instar larva. Please note that the fluorescence was transiently increased in local areas, indicating local firings.

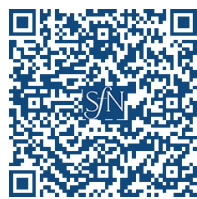

to express the 36-repeat arginine or alanine-rich DPRs (Mizielinska et al., 2014) in various neuronal populations. Surprisingly, GR36 or PR36 did not cause any neurotoxicity in dopaminergic, cholinergic, or GABAergic neurons (Table 1). In contrast, the expression of GR36 using a pan-neuron, motor neuron, or glutamatergic neuron-specific driver led to pupal lethality. The toxicity of PR36 was weaker than that of GR36 as PR36-expressing flies could survive till adulthood, but with impaired motor function and shortened life span (Fig. 1 $A, B$ ). Reducing the expression level of GR36 by lowering the culturing temperature produced a few viable flies (data not shown). Since Drosophila motor neurons are mostly glutamatergic (Mahr and Aberle, 2006; Sanyal, 2009), the phenotypes in GR36 and PR36-expressing flies suggested that glutamatergic motor neurons were selectively vulnerable to DPR toxicity.

We then directly assessed the effect of PR36 on motor neuron survival by coexpressing PR36 or PA36 with a membrane-bound GFP (mCD8::GFP) for easy visualization. PR36 expression caused a clear decrease in the number of GFP-labeled motor 

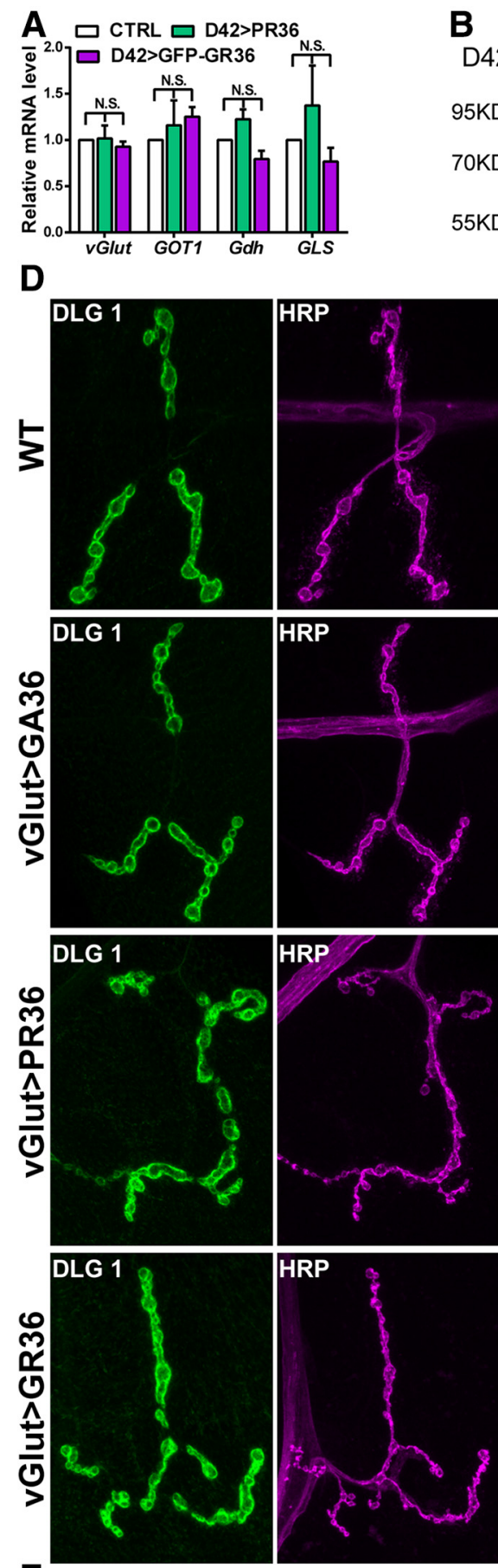

E

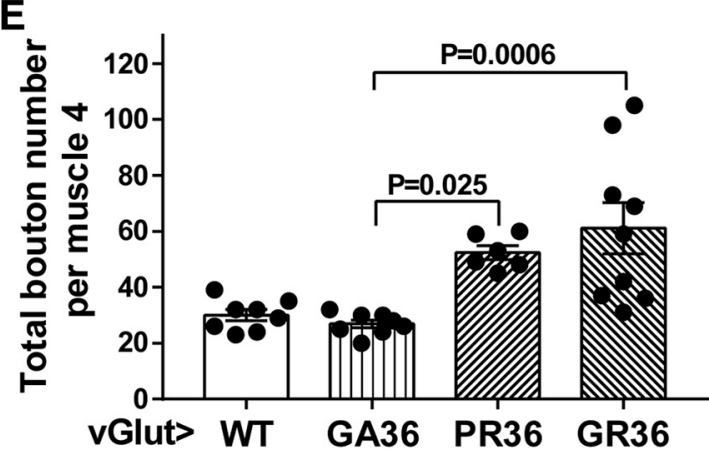

B

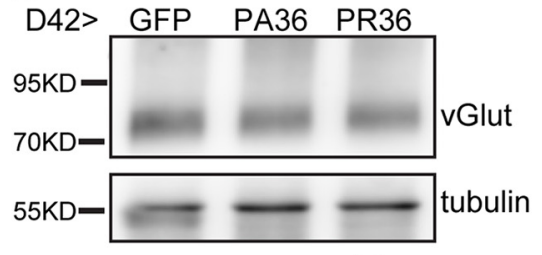

F
C
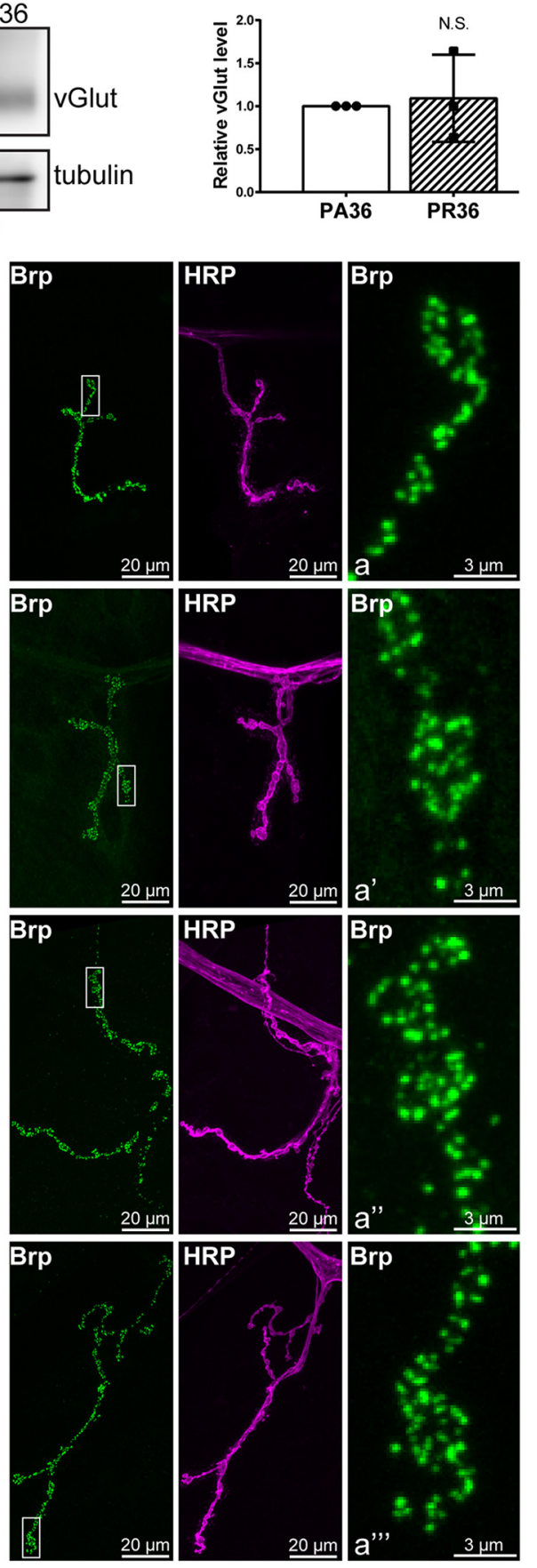

G

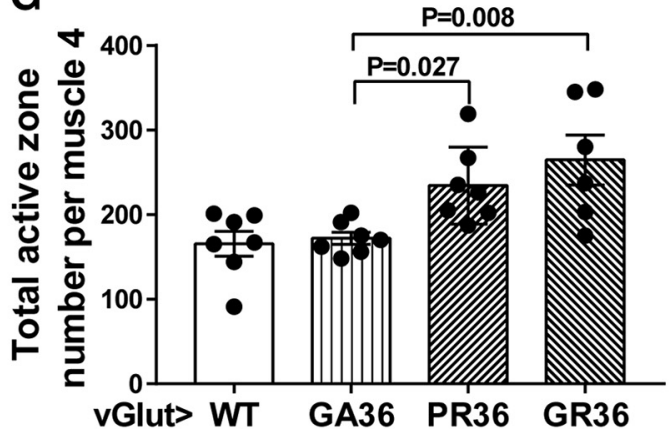

Figure 5. Arginine-containing DPRs increase the number of synaptic boutons and active zones in larval neuromuscular junctions. $A$, The expression of genes involved in glutamate synthesis and trafficking were not changed in arginine-rich DPR-expressing flies. Male, control genotype: D42-Gal4/+. Mean \pm SEM, $n=3$ independent experiments for each genotype, one-way ANOVA. $B, C$, The protein level of vGlut was not affected by PR36. Quantifications are shown in C. Mean \pm SEM, $n=3$ independent experiments, unpaired $t$ test. $\boldsymbol{D}$, Representative (Figure legend continues.) 
neurons as well as reduced fluorescence intensity at antennal lobe with aging (Fig. $1 C, D$ ), indicating neurodegeneration. In contrast, the expression of PR36 in $\mathrm{TH}+$ dopaminergic neurons did not cause any cell loss (Fig. $1 E, F$ ).

To better evaluate the effects of various DPR constructs and monitor their expression patterns, we tagged DPR constructs with GFP and made new fly lines expressing each GFP-DPR at the identical insertion site. The equal expression of the various constructs in the brain was validated by immunoblotting (data not shown). The expression of GFP-GR36 or GFP-PR36 in the eyes reproduced the general degenerative phenotypes seen in flies expressing untagged DPRs, though with lower toxicity (Fig. 2A). By evaluating various degenerative phenotypes (degeneration in the eyes, survival curve, and climbing ability; Fig. $2 A-C$ ), we found the following toxicity ranking: GR36>GFP-GR36 $\geq$ PR36 $>$ GFPPR36. Furthermore, consistent with the motor neuron loss in PR36-expressing flies (Fig. 1C,D), GFP-GR36 caused the loss of vGlut neurons (data not shown). We then conducted life span and climbing assays using flies expressing GFP-GR36 at various neuronal populations. Consistent with selective toxicity of arginine-rich DPR in glutamatergic motor neurons (Table 1), only the motor neuron-expressing GFP-GR36 led to significant shortened life span and reduced climbing ability (Fig. 2D,E).

To further validate the selective toxicity of arginine-rich DPRs in glutamatergic neurons, we used a pan-neuronal Elav driver to express GFP-GR36 and vGlut-driven Gal80 (Lee and Luo, 1999) to specifically inhibit the expression of GFP-GR36 in glutamatergic neurons. Whereas pan-neuronal expression of GFP-GR36 caused reduced climbing ability and significantly shortened life span, blocking its expression in glutamatergic neurons almost completely rescued the deficits (Fig. 3). Together, our studies revealed a selective toxicity of arginine-rich DPRs in glutamatergic neurons in Drosophila.

Given the selective toxicity seen in glutamatergic neurons, we examined whether glutamate release could be altered by the expression of arginine-rich DPRs in vGlut+ neurons using the intensity-based glutamate-sensing fluorescent reporter (iGlusnFR) system (Marvin et al., 2013; Stork et al., 2014). In this system, membrane-bound expression of glutamate-specific sensor detects extracellular glutamate and triggers green fluorescence. The efficacy of the system was validated using in vivo and ex vivo approaches (Fig. 4A, $B$; Movies 1,2). In both ventral nerve cord of third instar larvae and the adult brains of flies coexpressing PR36 and the iGluSnFR sensor in the glutamatergic neurons, there was a significant increase of extracellular glutamate content (Fig. 4C$F$ ). The glutamate signals also appeared to be dynamic (Movies 3, 4). Furthermore, we detected an increased intracellular calcium level using GCaMP6s (Fig. 4G,H). Therefore, the expression of PR36 in Drosophila glutamatergic neurons led to increased glutamate release from these cells and elevated intracellular calcium levels, suggesting excitotoxicity.

\section{$\leftarrow$}

(Figure legend continued.) images of muscle 4 NMJ synaptic boutons at abdominal segment A3 labeled with two presynaptic markers (HRP and vGlut) and postsynaptic marker DLG 1. $\boldsymbol{E}$, Quantification of the number of total synaptic boutons per NMJ in muscle 4. Mean \pm SEM; $n=8$ larvae for wild type, GA36 or GR36; $n=6$ larvae for PR36; one-way ANOVA. $\boldsymbol{F}$, Representative muscle 4 NMJs of the abdominal segment A3 double-stained with Brp and HRP. $\boldsymbol{a}, \boldsymbol{a}^{\prime}$, $\boldsymbol{a}^{\prime \prime}$, and $\boldsymbol{a}^{\prime \prime \prime}$ are magnified images of the rectangle areas with the indicated genotype; each punctate indicates one active zone. $\mathbf{G}$, Quantification of the number of total active zones per NMJ in muscle 4. Mean \pm SEM; $n=7$ larvae for wild type, GA36, or PR36; $n=6$ larvae for GR36; one-way ANOVA.
To investigate the underlying mechanism, we first examined the expression of proteins involved in glutamate transport and production. The mRNA expression of $v G l u t, G O T 1$, Gdh, and GLS did not show meaningful change in arginine-rich DPRexpressing flies (Fig. 5A), and there was no change for vGlut protein (Fig. 5B,C). As Drosophila NMJ is an ideal model for glutamatergic synapse, we examined the synaptic structures at muscle 4 in larvae using specific presynaptic markers HRP and vGlut and postsynaptic marker DLG 1. Expression of GR36, PR36, or GFP-GR36 (data not shown) in the glutamatergic neurons leads to a clear increase of the number of synaptic boutons (Fig. $5 D, E$ ) and active zones (Fig. $5 F, G$ ). As increased abundance of active zones is highly associated with increased presynaptic vesicle release (Cooper et al., 1995, 1996), the altered synaptic structure at NMJ supported the observation of elevated glutamate release in PR36-expressing flies.

A recent study reported loss of synaptic structure at the NMJ in Drosophila expressing GR100 (Perry et al., 2017). Given the apparent discrepancy, we expressed the highly toxic, pupal-lethal GR100 in glutamatergic neurons, and examined the synaptic structures. Consistent with the study by Perry et al. (2017), the vGlut-Gal4-driven GR100 caused a significant decrease in the number of active zones (Fig. 6). Therefore, high-repeat number DPR species may cause neurodegeneration via a mechanism involving synaptic degeneration, whereas low-repeat number and moderately toxic DPR species could cause overgrowth of synaptic structures and increased glutamate excitotoxicity.

As we have observed degeneration of glutamatergic motor neurons (Fig. 1C), we tested whether modulating the glutamate signaling in these neurons could block the GR36-induced toxicity. Silencing the expression of vGlut in motor neurons using either of the two RNAi lines almost completely reversed the climbing deficits and shortened life span caused by motor neuron-expressed GFP-GR36, indicating that the toxicity requires glutamate release (Fig. $7 A, B$ ). Since we have detected increased intracellular calcium in PR36-expressing glutamatergic neurons (Fig. 4G,H), and that calcium-permeable NMDA receptors could be expressed at presynaptic terminals to act as autoreceptors to regulate neurotransmitter release (Bouvier et al., 2015), we examined whether presynaptic NMDA receptors may be involved in the toxicity. Silencing of NMDA receptor 1 in motor neurons mainly reversed shortened life span (Fig. 7B). Furthermore, treating flies with NMDA receptor antagonist memantine (Reisberg et al., 2003) or reducing the overall expression of NMDA receptor with a heterozygous mutant line could significantly extend the life span of flies expressing GFP-GR36 in glutamatergic neurons (Fig. 7C). Feeding larvae with memantine could also increase male pupae-to-adult viability (Table 2). Together, our results suggested that arginine-rich DPRs could cause cell-autonomous excitotoxicity by increasing glutamate release and triggering the activation of NMDA receptors in glutamatergic neurons.

\section{Discussion}

In this study, by taking advantage of various genetic tools available for Drosophila studies, we have found that arginine-rich DPRs cause selective degeneration in Drosophila glutamatergic neurons and revealed altered synaptic structures, increased glutamate release, and presynaptic NMDA receptor-dependent glutamate excitotoxicity as the main culprit.

Excitotoxicity is considered one of the major mechanisms for motor neuron degeneration in ALS (Rothstein et al., 1990; Taylor et al., 2016). In mammals, the degeneration of motor neurons is 
A

CTRL

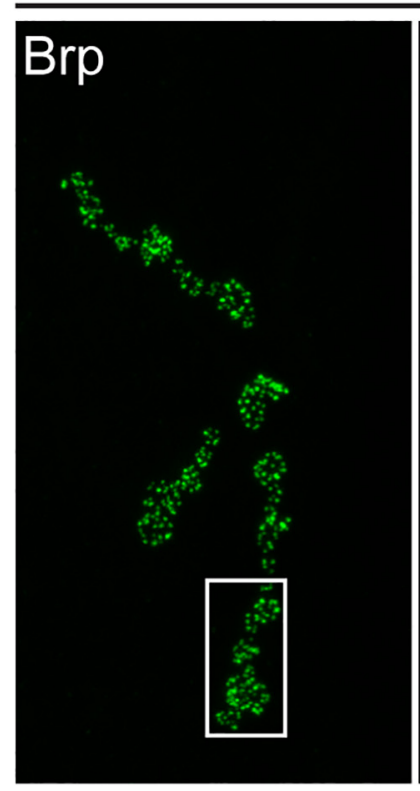

B

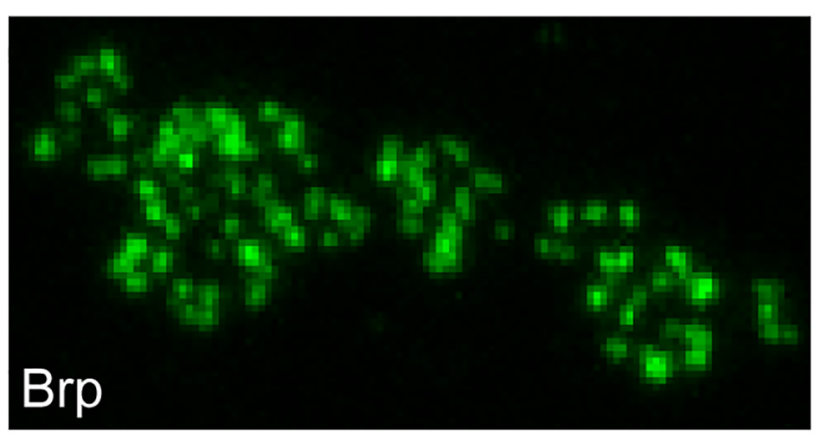

vGlut>GR100
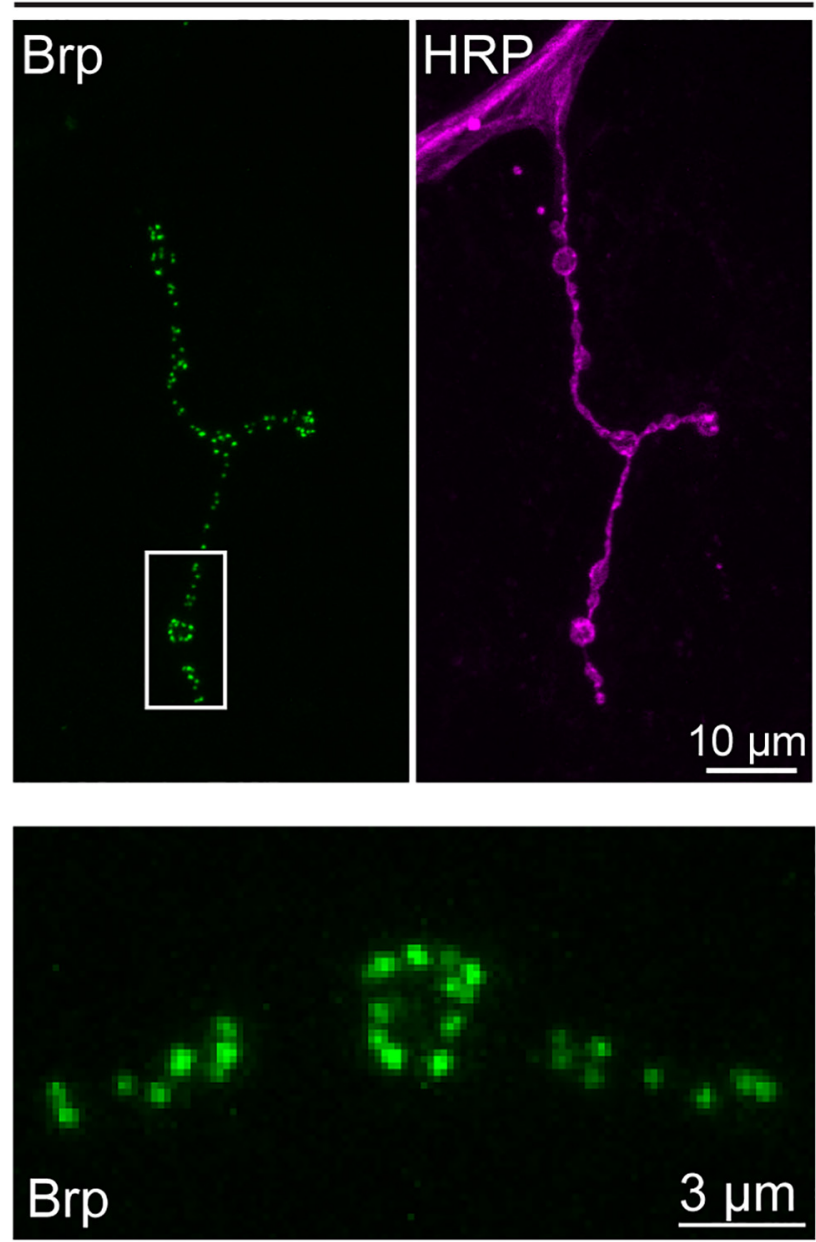

C

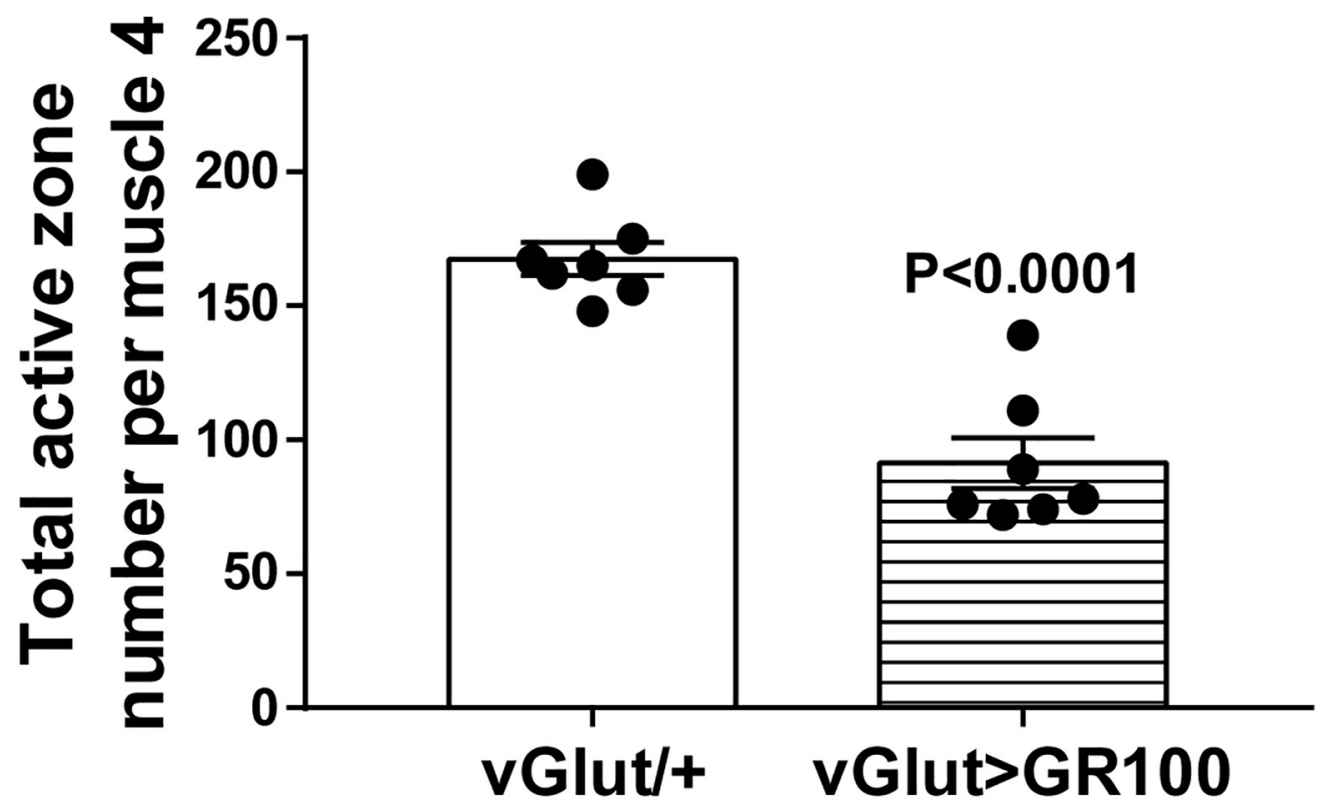

Figure 6. GR100 causes decreased number of active zones. $A, B$, Confocal images of muscle 4 NMJs double-stained with Brp and HRP. The magnified images of the rectangle areas are shown in $B$. Control genotype: vGlut-Gal4/+. C, Quantification of the total number of active zones per NMJ in muscle 4. Mean \pm SEM, $n=7$ larvae, unpaired $t$ test. 

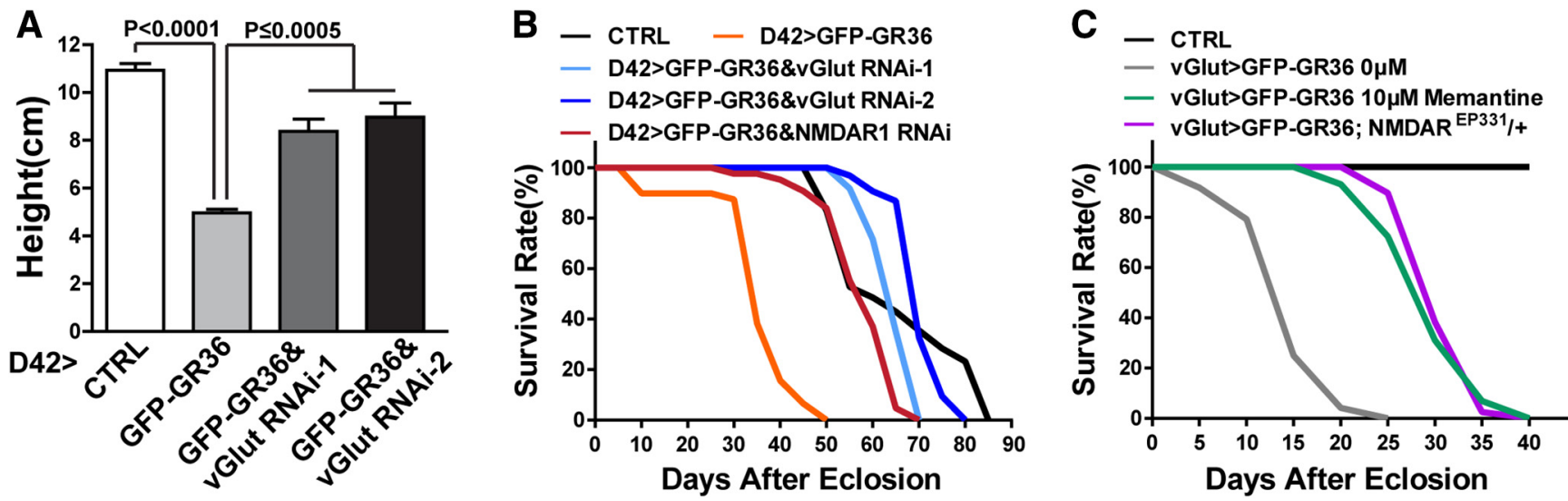

Figure 7. Inhibition of glutamate excitotoxicity prevents GFP-GR36-caused neurodegenerative phenotypes. $A$, Silencing the expression of vGlut in motor neurons by using two independent RNAi lines prevented GFP-GR36-caused motor defects. Male, control genotype: D42-Gal4/+. Mean \pm SEM, $n=3$ tubes for each genotype, one-way ANOVA. B, The life span of flies with silenced vGlut or NMDA receptor in motor neurons. Male, control genotype: D42-Gal4/+, $n=3$ tubes for each genotype. C, The life span of GFP-GR36-expressing flies with or without NMDA receptor antagonist memantine treatment or with the mutation-caused reduced NMDAR level. Female, control genotype: vGlut-Gal4/,$+ n=3$ tubes for each genotype.

Table 2. The effects of memantine on pupae formation and development in GFP-GR36-expressing flies

\begin{tabular}{|c|c|c|c|}
\hline & Treatment & $\begin{array}{l}\text { Pupae } \\
\text { formation }\end{array}$ & $\begin{array}{l}\text { Pupae-to-adult } \\
\text { viability }\end{array}$ \\
\hline \multirow[t]{2}{*}{ vGlut-Gal4 × UAS-GFP-GR36 } & Control & 63 & $\begin{array}{l}\text { ô Lethal } \\
\text { \& } 24 \text { of } 63 \text { (39.7\%) }\end{array}$ \\
\hline & Memantine (10 $\mu \mathrm{M})$ & 67 & $\begin{array}{l}\text { o } \mathbf{1 8} \text { of } \mathbf{6 7}(\mathbf{2 6 . 7 \% )} \\
\text { \& } 29 \text { of } 67(40.3 \%)\end{array}$ \\
\hline
\end{tabular}

Bold labels the beneficial effects.

commonly considered a noncell-autonomous event caused by the loss of glial glutamate transporter or altered expression of AMPA receptors (Cleveland and Rothstein, 2001). Recent studies using C9 patient-derived iPSCs motor neurons showed increased susceptibility of these neurons to glutamate toxicity, likely contributed by AMPA receptor activation (Donnelly et al., 2013; Selvaraj et al., 2018; Shi et al., 2018) and/or decreased glutamate uptake by astrocytes (Shi et al., 2018). Interestingly, in our in vivo model of C9 DPRs, we have found that a presynaptic cellautonomous mechanism in glutamatergic neurons contributes to the neurodegenerative phenotypes. The expression of poly GR36 or PR36 in Drosophila glutamatergic neurons would lead to altered synaptic structures and increased extracellular glutamate and cause selective degeneration in an NMDA receptor-dependent manner. Although NMDA receptors were best characterized as a postsynaptic component to relay excitatory potentials, mounting evidence has shown that presynaptic NMDA receptors are widely present in the CNS (Bouvier et al., 2015). At excitatory terminals, NMDA receptors could be activated by glutamate released from axon terminals as autoreceptors to increase calcium influx and to further regulate neurotransmitter release and excitotoxicity (Suárez et al., 2005; Bouvier et al., 2015). Our results support a model whereby C9 DPRs could stimulate synapses' overgrowth, promote glutamate release, and activate presynaptic NMDA receptors to exacerbate excitotoxicity. This glutamatergic neuron-specific mechanism would be particularly relevant to C9 ALS and FTD, as increased glutamate release from DPR-expressing excitatory neurons could cause excitotoxicity not only to postsynaptic neurons (including motor neurons), but also to presynaptic neurons in a cell-autonomous manner. This mechanism may contribute to the cortical hyperexcitability in ALS and FTD patients with C9orf72 mutations (Geevasinga et al., 2015; Schanz et al., 2016).
It is intriguing that we have only observed neurotoxic phenotypes when poly GR/PR were expressed in vGlut+ motor neurons, as DPRs have been reported to affect general mechanisms such as nuclear-cytoplasmic transportation or stress granule dynamics (Taylor et al., 2016). Previous genetic screening to identify the functional modifiers of C9 DPRs in Drosophila were usually performed in compound eyes and may involve expression of highly toxic long repeats that cause pupal lethality (Freibaum et al., 2015; Zhang et al., 2015; Boeynaems et al., 2016). Therefore, these general mechanisms may be more relevant to cellular conditions with highly toxic DPR species, either the ones with long repeats or those expressed at an elevated level. By using multiple viable fly lines expressing moderate- to medium-level toxicity, we have reproducibly observed glutamatergic-selective neurotoxicity. Therefore, the mechanism we have discovered would reflect the biological effects of poly GR/PR at more physiological levels or moderate toxicity. In fact, when we expressed the pupal-lethal GR100 in glutamatergic neurons, instead of overgrowth of synaptic structures as seen in the NMJ of GR36-expressing larvae, we have observed loss of the active zones. The increased excitotoxicity could be an early event during C9 DPR-induced neurotoxicity, eventually leading to synapse and axon degeneration with aging. Consistent with this notion, in PR36-expressing glutamatergic motor neurons of adult flies, we have seen increased loss of neuronal projection to antennal lobe with aging (Fig. $1 C, D$ ), indicating axon degeneration. It is also worth noting that prior studies using 30 GGGGCC repeats have reported a decreased number of active zones (Zhang et al., 2015; Celona et al., 2017). As these repeats could produce an unknown combination of DPRs and even RNA species, it would be reasonable to observe a stronger mixed effect on active zone. However, it would be difficult to assess the individual effects of DPRs in those models. In contrast, our current study provides new evidence to understand the direct roles of C9 DPRs in the regulation of synaptic signaling.

The pathogenic mechanisms for C9orf72 products are complicated because of the unusual production of RNA and various proteins species (Haeusler et al., 2016; Freibaum and Taylor, 2017; Gendron and Petrucelli, 2018; Starr and Sattler, 2018). Most likely, the variety of symptoms exhibited in patients carrying C9 mutations are the combination of several factors caused by C9 repeat expansion. In this study, we used Drosophila CNS as a simplified tool to evaluate the effects of C9 DPRs in the brain. Our findings showing the novel regulation of glutamate release 
by poly GR/PR and the cell-autonomous excitotoxicity of DPRexpressing glutamatergic neurons would expand the current understanding of the functions of C9 products. Given the gradual recognition of arginine-rich DPRs as key toxic C9 products, their effects on glutamate signaling and the potential synergistic effect with RNA species on synaptic function warrant further examination in mammalian models of C9 DPRs in the future.

As riluzole targets glutamate signaling, our study provides additional evidence to support the combined use of riluzole and memantine, especially for ALS/FTD patients with C9 mutations.

\section{References}

Bensimon G, Lacomblez L, Meininger V (1994) A controlled trial of riluzole in amyotrophic lateral sclerosis. ALS/riluzole study group. N Engl J Med 330:585-591. CrossRef Medline

Boeynaems S, Bogaert E, Michiels E, Gijselinck I, Sieben A, Jovičić A, De Baets G, Scheveneels W, Steyaert J, Cuijt I, Verstrepen KJ, Callaerts P, Rousseau F, Schymkowitz J, Cruts M, Van Broeckhoven C, Van Damme P, Gitler AD, Robberecht W, Van Den Bosch L (2016) Drosophila screen connects nuclear transport genes to DPR pathology in c9ALS/FTD. Sci Rep 6:20877. CrossRef Medline

Boeynaems S, Bogaert E, Kovacs D, Konijnenberg A, Timmerman E, Volkov A, Guharoy M, De Decker M, Jaspers T, Ryan VH, Janke AM, Baatsen P, Vercruysse T, Kolaitis RM, Daelemans D, Taylor JP, Kedersha N, Anderson P, Impens F, Sobott F, et al. (2017) Phase separation of C9orf72 dipeptide repeats perturbs stress granule dynamics. Mol Cell 65:10441055.e5. Medline

Bouvier G, Bidoret C, Casado M, Paoletti P (2015) Presynaptic NMDA receptors: roles and rules. Neuroscience 311:322-340. CrossRef Medline

Brand AH, Perrimon N (1993) Targeted gene expression as a means of altering cell fates and generating dominant phenotypes. Development 118: 401-415. Medline

Celona B, Dollen JV, Vatsavayai SC, Kashima R, Johnson JR, Tang AA, Hata A, Miller BL, Huang EJ, Krogan NJ, Seeley WW, Black BL (2017) Suppression of C9orf72 RNA repeat-induced neurotoxicity by the ALSassociated RNA-binding protein Zfp106. Elife 6:e19032. CrossRef Medline

Cleveland DW, Rothstein JD (2001) From Charcot to Lou Gehrig: deciphering selective motor neuron death in ALS. Nat Rev Neurosci 2:806819. CrossRef Medline

Cooper RL, Marin L, Atwood HL (1995) Synaptic differentiation of a single motor neuron: conjoint definition of transmitter release, presynaptic calcium signals, and ultrastructure. J Neurosci 15:4209-4222. CrossRef Medline

Cooper RL, Winslow JL, Govind CK, Atwood HL (1996) Synaptic structural complexity as a factor enhancing probability of calcium-mediated transmitter release. J Neurophysiol 75:2451-2466. CrossRef Medline

Daniels RW, Gelfand MV, Collins CA, DiAntonio A (2008) Visualizing glutamatergic cell bodies and synapses in Drosophila larval and adult CNS. J Comp Neurol 508:131-152. CrossRef Medline

DeJesus-Hernandez M, Mackenzie IR, Boeve BF, Boxer AL, Baker M, Rutherford NJ, Nicholson AM, Finch NA, Flynn H, Adamson J, Kouri N, Wojtas A, Sengdy P, Hsiung GY, Karydas A, Seeley WW, Josephs KA, Coppola G, Geschwind DH, Wszolek ZK, et al. (2011) Expanded GGGGCC hexanucleotide repeat in noncoding region of C9ORF72 causes chromosome 9p-linked FTD and ALS. Neuron 72:245-256. CrossRef Medline

Donnelly CJ, Zhang PW, Pham JT, Haeusler AR, Mistry NA, Vidensky S, Daley EL, Poth EM, Hoover B, Fines DM, Maragakis N, Tienari PJ, Petrucelli L, Traynor BJ, Wang J, Rigo F, Bennett CF, Blackshaw S, Sattler R, Rothstein JD (2013) RNA toxicity from the ALS/FTD C9ORF72 expansion is mitigated by antisense intervention. Neuron 80:415-428. CrossRef Medline

Freibaum BD, Taylor JP (2017) The role of dipeptide repeats in C9ORF72related ALS-FTD. Front Mol Neurosci 10:35. CrossRef Medline

Freibaum BD, Lu Y, Lopez-Gonzalez R, Kim NC, Almeida S, Lee KH, Badders N, Valentine M, Miller BL, Wong PC, Petrucelli L, Kim HJ, Gao F-B, Taylor JP (2015) GGGGCC repeat expansion in C9orf72 compromises nucleocytoplasmic transport. Nature 525:129-133. CrossRef Medline

Geevasinga N, Menon P, Howells J, Nicholson GA, Kiernan MC, Vucic S
(2015) Axonal ion channel dysfunction in c9orf72 familial amyotrophic lateral sclerosis. JAMA Neurol 72:49-57. CrossRef Medline

Gendron TF, Petrucelli L (2018) Disease mechanisms of C9ORF72 repeat expansions. Cold Spring Harb Perspect Med 8:a024224. CrossRef Medline

Haeusler AR, Donnelly CJ, Rothstein JD (2016) The expanding biology of the C9orf72 nucleotide repeat expansion in neurodegenerative disease. Nat Rev Neurosci 17:383-395. CrossRef Medline

Jovicic A, Mertens J, Boeynaems S, Bogaert E, Chai N, Yamada SB, Paul JW 3rd, Sun S, Herdy JR, Bieri G, Kramer NJ, Gage FH, Van Den Bosch L, Robberecht W, Gitler AD (2015) Modifiers of C9orf72 dipeptide repeat toxicity connect nucleocytoplasmic transport defects to FTD/ALS. Nat Neurosci 18:1226-1229. CrossRef Medline

Kwon I, Xiang S, Kato M, Wu L, Theodoropoulos P, Wang T, Kim J, Yun J, Xie Y, McKnight SL (2014) Poly-dipeptides encoded by the C9orf72 repeats bind nucleoli, impede RNA biogenesis, and kill cells. Science 345 : 1139-1145. CrossRef Medline

Lee KH, Zhang P, Kim HJ, Mitrea DM, Sarkar M, Freibaum BD, Cika J, Coughlin M, Messing J, Molliex A, Maxwell BA, Kim NC, Temirov J, Moore J, Kolaitis RM, Shaw TI, Bai B, Peng J, Kriwacki RW, Taylor JP (2016) C9orf72 dipeptide repeats impair the assembly, dynamics, and function of membrane-less organelles. Cell 167:774-788.e17. CrossRef Medline

Lee T, Luo L (1999) Mosaic analysis with a repressible cell marker for studies of gene function in neuronal morphogenesis. Neuron 22:451-461. CrossRef Medline

Lin Y, Mori E, Kato M, Xiang S, Wu L, Kwon I, McKnight SL (2016) Toxic PR poly-dipeptides encoded by the C9orf72 repeat expansion target LC domain polymers. Cell 167:789-802.e12. CrossRef Medline

Liu Y, Pattamatta A, Zu T, Reid T, Bardhi O, Borchelt DR, Yachnis AT, Ranum LP (2016) C9orf72 BAC mouse model with motor deficits and neurodegenerative features of ALS/FTD. Neuron 90:521-534. CrossRef Medline

Mahr A, Aberle H (2006) The expression pattern of the drosophila vesicular glutamate transporter: a marker protein for motoneurons and glutamatergic centers in the brain. Gene Expr Patterns 6:299-309. CrossRef Medline

Markmiller S, Soltanieh S, Server KL, Mak R, Jin W, Fang MY, Luo EC, Krach F, Yang D, Sen A, Fulzele A, Wozniak JM, Gonzalez DJ, Kankel MW, Gao FB, Bennett EJ, LécuyerE, Yeo GW (2018) Context-dependent and disease-specific diversity in protein interactions within stress granules. Cell 172:590-60.e13. CrossRef Medline

Marvin JS, Borghuis BG, Tian L, Cichon J, Harnett MT, Akerboom J, Gordus A, Renninger SL, Chen T-W, Bargmann CI, Orger MB, Schreiter ER, Demb JB, Gan W-B, Hires SA, Looger LL (2013) An optimized fluorescent probe for visualizing glutamate neurotransmission. Nat Methods 10:162-170. CrossRef

Mizielinska S, GrönkeS, Niccoli T, Ridler CE, Clayton EL, Devoy A, Moens T, Norona FE, Woollacott IOC, Pietrzyk J, Cleverley K, Nicoll AJ, Pickering-Brown S, Dols J, Cabecinha M, Hendrich O, Fratta P, Fisher EMC, Partridge L, Isaacs AM (2014) C9orf72 repeat expansions cause neurodegeneration in drosophila through arginine-rich proteins. Science 345:1192-1194. CrossRef Medline

O'Rourke JG, Bogdanik L, Muhammad AKMG, Gendron TF, Kim KJ, Austin A, Cady J, Liu EY, Zarrow J, Grant S, Ho R, Bell S, Carmona S, Simpkinson M, Lall D, Wu K, Daughrity L, Dickson DW, Harms MB, Petrucelli L, et al. (2015) C9orf72 BAC transgenic mice display typical pathologic features of ALS/FTD. Neuron 88:892-901. CrossRef Medline

Perry S, Han Y, Das A, Dickman D (2017) Homeostatic plasticity can be induced and expressed to restore synaptic strength at neuromuscular junctions undergoing ALS-related degeneration. Hum Mol Genet 26: 4153-4167. CrossRef Medline

Peters OM, Cabrera GT, Tran H, Gendron TF, McKeon JE, Metterville J, Weiss A, Wightman N, Salameh J, Kim J, Sun H, Boylan KB, Dickson D, Kennedy Z, Lin Z, Zhang YJ, Daughrity L, Jung C, Gao FB, Sapp PC, et al. (2015) Human C9ORF72 hexanucleotide expansion reproduces RNA foci and dipeptide repeat proteins but not neurodegeneration in BAC transgenic mice. Neuron 88:902-909. CrossRef Medline

Picconi B, Piccoli G, Calabresi P (2012) Synaptic dysfunction in Parkinson's disease. Adv Exp Med Biol 970:553-572. CrossRef Medline

Raymond LA, André VM, Cepeda C, Gladding CM, Milnerwood AJ, Levine MS (2011) Pathophysiology of Huntington's disease: time-dependent 
alterations in synaptic and receptor function. Neuroscience 198:252-273. CrossRef Medline

Reisberg B, Doody R, Stöffler A, Schmitt F, Ferris S, Möbius HJ (2003) Memantine in moderate-to-severe Alzheimer's disease. N Engl J Med 348: 1333-1341. CrossRef Medline

Renton AE, Majounie E, Waite A, Simón-Sánchez J, Rollinson S, Gibbs JR, Schymick JC, Laaksovirta H, van Swieten JC, Myllykangas L, Kalimo H, Paetau A, Abramzon Y, Remes AM, Kaganovich A, Scholz SW, Duckworth J, Ding J, Harmer DW, Hernandez DG, et al. (2011) A hexanucleotide repeat expansion in C9ORF72 is the cause of chromosome 9p21-linked ALS-FTD. Neuron 72:257-268. CrossRef Medline

Rothstein JD, Tsai G, Kuncl RW, Clawson L, Cornblath DR, Drachman DB, Pestronk A, Stauch BL, Coyle JT (1990) Abnormal excitatory amino acid metabolism in amyotrophic lateral sclerosis. Ann Neurol 28:18-25. CrossRef Medline

Sanyal S (2009) Genomic mapping and expression patterns of C380, OK6 and D42 enhancer trap lines in the larval nervous system of Drosophila. Gene Expr Patterns 9:371-380. CrossRef Medline

Schanz O, Bageac D, Braun L, Traynor BJ, Lehky TJ, Floeter MK (2016) Cortical hyperexcitability in patients with C9ORF72 mutations: relationship to phenotype. Muscle Nerve 54:264-269. CrossRef Medline

Selkoe DJ (2002) Alzheimer's disease is a synaptic failure. Science 298:789791. CrossRef Medline

Selvaraj BT, Livesey MR, Zhao C, Gregory JM, James OT, Cleary EM, Chouhan AK, Gane AB, Perkins EM, Dando O, Lillico SG, Lee YB, Nishimura AL, Poreci U, Thankamony S, Pray M, Vasistha NA, Magnani D, Borooah S, Burr K, et al. (2018) C9ORF72 repeat expansion causes vulnerability of motor neurons to $\mathrm{Ca} 2+$-permeable AMPA receptor-mediated excitotoxicity. Nat Commun 9:347. CrossRef Medline

Shi KY, Mori E, Nizami ZF, Lin Y, Kato M, Xiang S, Wu LC, Ding M, Yu Y, Gall JG, McKnight SL (2017) Toxic PRn poly-dipeptides encoded by the C9orf72 repeat expansion block nuclear import and export. Proc Natl Acad Sci U S A 114:E1111-E1117. CrossRef Medline

Shi Y, Lin S, Staats KA, Li Y, Chang WH, Hung ST, Hendricks E, Linares GR, Wang Y, Son EY, Wen X, Kisler K, Wilkinson B, Menendez L, Sugawara T, Woolwine P, Huang M, Cowan MJ, Ge B, Koutsodendris N, et al. (2018)
Haploinsufficiency leads to neurodegeneration in C9ORF72 ALS/FTD human induced motor neurons. Nature Med 24:313-325. CrossRef Medline

Starr A, Sattler R (2018) Synaptic dysfunction and altered excitability in C9ORF72 ALS/FTD. Brain Res 1693:98-108. CrossRef Medline

Stork T, Sheehan A, Tasdemir-Yilmaz OE, Freeman MR (2014) Neuronglia interactions through the heartless FGF receptor signaling pathway mediate morphogenesis of drosophila astrocytes. Neuron 83:388-403. CrossRef Medline

Suárez LM, Suárez F, Del Olmo N, Ruiz M, González-Escalada JR, Solís JM (2005) Presynaptic NMDA autoreceptors facilitate axon excitability: a new molecular target for the anticonvulsant gabapentin. Eur J Neurosci 21:197-209. CrossRef Medline

Tao Z, Wang H, Xia Q, Li K, Jiang X, Xu G, Wang G, Ying Z (2015) Nucleolar stress and impaired stress granule formation contribute to C9orf72 RAN translation-induced cytotoxicity. Hum Mol Genet 24:2426-2441. CrossRef Medline

Taylor JP, Brown RH Jr, Cleveland DW (2016) Decoding ALS: from genes to mechanism. Nature 539:197-206. CrossRef Medline

Tran H, Almeida S, Moore J, Gendron TF, Chalasani U, Lu Y, Du X, Nickerson JA, Petrucelli L, Weng Z, Gao FB (2015) Differential toxicity of nuclear RNA foci versus dipeptide repeat proteins in a drosophila model of C9ORF72 FTD/ALS. Neuron 87:1207-1214. CrossRef Medline

Wang T, Xu W, Qin M, Yang Y, Bao P, Shen F, Zhang Z, Xu J (2016) Pathogenic mutations in the valosin-containing protein/p97(VCP) N-domain inhibit the SUMOylation of VCP and lead to impaired stress response. J Biol Chem 291:14373-14384. CrossRef Medline

Xu Z, Poidevin M, Li X, Li Y, Shu L, Nelson DL, Li H, Hales CM, Gearing M, Wingo TS, Jin P (2013) Expanded GGGGCC repeat RNA associated with amyotrophic lateral sclerosis and frontotemporal dementia causes neurodegeneration. Proc Natl Acad Sci U S A 110:7778-7783. CrossRef Medline

Zhang K, Donnelly CJ, Haeusler AR, Grima JC, Machamer JB, Steinwald P, Daley EL, Miller SJ, Cunningham KM, Vidensky S, Gupta S, Thomas MA, Hong I, Chiu SL, Huganir RL, Ostrow LW, Matunis MJ, Wang J, Sattler R, Lloyd TE, et al. (2015) The C9orf72 repeat expansion disrupts nucleocytoplasmic transport. Nature 525:56-61. CrossRef Medline 